\title{
DIE RESTAURIERUNG DES SCHLOSSES ESTERHÁZY IN ESZTERHÁZA UND SEINE INTERIEURSREPRODUKTIONEN IN BUDAPEST UND WIEN AM ENDE DES 19. JAHRHUNDERTS
}

The restoration of the Castle Esterházy in Eszterháza and the reproductions of its Interiors in Budapest and Vienna at the End of the 19 $^{\text {th }}$ Century. The restoration of the Castle in Eszterháza was made between 1891-1896/1897 by the Viennese Company Friedrich Otto Schmidt. In course of the restoration work were furniture and wall revetments of the $18^{\text {th }}$ century restored, complemented by modern pieces and also copies of the original luxury Esterházy-furniture were made. The reputation of the Company went established by the restoration of Fertőd castle in the whole Austrian-Hungarian Monarchy. In the 1896 Millenary Exhibition of Budapest the copy of a suite of rooms of the castle was on show. This was later not accepted by the Budapest Museum of Applied Arts in his permanent exhibition because Director Jenő Radisics has considered the Rococo style of the castle as a break with the organic evolution of Hungarian art and was also opposed by principles to the substitution of historical objects by copies.

The Schmidt Company has exhibited 1898 in the Assembly Room of the Winter Exhibition of the Österreichisches Museum für Kunst und Industrie a so-called exact copy of the Apollo-Room of Eszterháza, really a series of copies of French Rococo luxury furniture. As a program of exact copy, this interior can be considered as a radical break with the former practice of Historicism. By this change a crisis was caused in the relationship of the Director Arthur von Scala to the Kunstgewerbeverein in Vienna and by the survival of Historicism also to the circle of the Secession.

Keywords: Esterházy, Eszterháza / Fertőd, Scala, Loos, Wagner, Radisics, Rococo furniture, Friedrich Otto Schmidt, interior decoration $18^{\text {th }}-20^{\text {th }}$ century, Vienna Interior 1900, Kunstgewerbeverein, Bubics

Im Rückblick auf seine Laufbahn bezeichnete der todkranke Max Schmidt im November 1934, am Ende seines Lebens, die Restaurierung des Schlosses Esterházy in Eszterháza als seine bedeutendste Ar beit: „Das Meisterwerk meines Lebens war die Restaurierung des Schlosses Esterházy. Es handelt sich um ein Schloss mit 120 Zimmern, das der Fürst Esterházy bauen ließ, um Maria Theresia zu zeigen, dass man auch in Ungarn schön leben und wohnen kann. [...] Das Schloss war jedoch von den Nachfahren vollkommen vernachlässigt und befand sich in einem baufälligen Zustand, als der Großvater des jetzigen Fürsten Pál Esterházy, der ebenfalls Pál hieß, mich mit der Restaurierung beauf-

* Péter Rostás, PhD art historian, director of the Museum Kiscell (Budapest History Museum). rostas@kiscellimuzeum.hu Für die gründlichen Korrekturarbeiten am vorliegenden Beitrag bin ich Edit Szentesi und Gábor Alföldy dankbar. tragte. Die Arbeit dauerte sechs Jahre. [...] Ich wurde dem Fürsten von Bubics, dem Bischof von Kassa, empfohlen und dieser Auftrag war der eigentliche Grund, warum ich aus Wien nach Ungarn kam, um hier sesshaft zu werden."1

Es ist unbekannt, wie der Kontakt zwischen Zsigmond Bubics und den Schmidts zustande kam, doch so viel scheint gewiss zu sein, dass die Firma Friedrich Otto Schmidt vom Bischof Bubics, der etwa zwischen 1884 und 1898 als Zwangsverwalter des Majorats der Esterházys tätig war, ${ }^{2}$ für die mehr als zehn Jahre dauernden Restaurierungsund Innenausstattungsarbeiten an den Immobilien des Majorats engagiert wurde. ${ }^{3} \mathrm{Zu}$ diesen Arbeiten gehörten die Restaurierung und die Einrichtung des Burgschlosses in Pottendorf, der Burg von Lockenhaus/Léka, des Schlosses wie auch des Wartesaals am Bahnhof von Eisenstadt und des EsterházyPalais in der Tárnok-Straße in Ofen sowie vor allem die Arbeiten im Schloss von Eszterháza. 


\section{DER ABLAUF DER RESTAURIERUNGSARBEITEN AM SCHLOSS VON ESZTERHÁZA ZWISCHEN 1891 UND 1894}

Angaben zum Ablauf der Restaurierungsarbeiten sind vor allem den Kassabüchern der Firma Schmidt zu entnehmen. ${ }^{4}$ Im Fall des Schlosses in Eszterháza, das für den Fürsten Miklós Pál Antal Esterházy (1869-1920) erneuert wurde, beginnen die seit Oktober 1891 geführten Abrechnungen - wie bei den anderen durch die Firma Schmidt restaurierten oder eingerichteten Objekten - mit den Kosten für die mehrfachen Reisen von Schmidt. Seitens der Firma erfolgten bereits in diesem Herbst Auszahlungen an in Eszterháza tätige Handwerker. ${ }^{5} \mathrm{Im}$ Winter und Frühling 1891-1892 fanden kontinuierlich Restaurierungsarbeiten statt, wobei der Besitzer der Ausstattungsfirma selbst mehrmals ins Schloss kam. ${ }^{6}$ Seitens des Fürsten erfolgte die an die Firma Friedrich Otto Schmidt für die Restaurierung in Eszterháza getätigte erste Auszahlung am 11. Juli 1892. ${ }^{7}$ Auch im Mai und im Sommer wurde gearbeitet: Am 11. Juli wurde der Rechnungsbetrag für den „linken Schlosstrakt“ gebucht. ${ }^{8}$ Somit wurden zuerst die Räumlichkeiten fürs Personal, d. h. für die Kammerdiener, die Hausmädchen, den Jäger usw., in bewohnbaren Zustand gebracht. ${ }^{9}$

Im Juli 1892 traf im Schloss auch der Bruder von Max Schmidt, Otto Erdmann Schmidt, ein, der der Firma zum Teil ihren Namen gab. ${ }^{10}$ Seine Teilnahme an den einschlägigen Arbeiten muss wohl die wichtigste Beschäftigung in seiner letzten Lebensphase gewesen sein. ${ }^{11}$ Im Herbst 1893 muss die Schlossrestaurierung eine neue Phase erreicht haben, in der die Ausstattungsarbeiten und die nuancierten Handwerksarbeiten wie Vergoldung und Tapezierung usw. ausgeführt werden mussten. ${ }^{12}$ Die Datenreihen im Kassabuch brechen jedoch Anfang 1894 ab.

Im Jahr 1894 ist die Restaurierung der Prunkräume des Mitteltraktes mit höchster Wahrscheinlichkeit abgeschlossen. Einen Hinweis darauf liefert jene fotografische Aufnahme von den repräsentativen Interieurs des Schlosses, die als Vorbereitung für die Millenniumsausstellung von 1896 angefertigt wurde.
Die Ausstellungsvorbereitungen selbst waren bereits 1894 voll im Gang. Die Vorbereitungskommission der historischen Gruppe - bestehend aus Jenő Radisics, János Szendrei und Kamill Fittler - unternahm landesweite Reisen, um von hervorragenden Denkmälern Gipsabdrücke oder fotografische Aufnahmen zu machen. Die Fachleute kamen auch nach Eszterháza, Eisenstadt und Forchtenstein. In Eszterháza schloss sich ihnen auch der Vorsitzende der Landeskommission der Millenniumsausstellung, der damalige Handelsminister, an. In seiner Anwesenheit und mit einer Sondergenehmigung von Pál Antal Esterházy konnte die Gruppe das Schloss besichtigen: „Als Ergebnis wurden ein Salon, ein Speisesaal, ein Schlafzimmer und eine Galerie aus dem 18. Jahrhundert mit der gesamten fürstlichen Ausstattung für die Reproduktion ausgewählt." ${ }^{13}$ Die Räume wurden fotografiert und die Originalmöbelstücke für die Reproduktion inventarisiert. Eine Inventur wurde von der Kommission auch in der Burg Forchtenstein vorgenommen. ${ }^{14}$ Der Bischof Zsigmond Bubics fungierte indessen als Mitglied der Kirchenkommission der Millenniumsausstellung. So ist es durchaus verständlich, dass die Interieurs des bedeutendsten Rokokoschlosses von Ungarn in Form von Reproduktionen als Teil des Programms der Millenniumsausstellung präsentiert wurden, um die Resultate der groß angelegten und unter der Aufsicht von Bubics ausgeführten Restaurierungsarbeiten aufzuzeigen. ${ }^{15}$

Die Arbeiten in Eszterháza wurden vermutlich im linken Trakt des Schlosses begonnen, mit dem Mitteltrakt fortgesetzt und im rechten Nebentrakt abgeschlossen. Ein Hinweis darauf ist, dass ein Rekonstruktionsplan des am rechten Seitentrakt angeschlossenen Gebäudes der ehemaligen Bildergalerie erst 1895, d. h. nach der Fertigstellung der Prunkräume, von Schmidt vorgelegt wurde. ${ }^{16}$

Im September 1896 drängte Schmidt zur Beauftragung der Restaurierung der Bildergalerie. ${ }^{17}$ Offensichtlich kam es aber nicht mehr dazu, weil die finanziellen Mittel erschöpft waren. ${ }^{18}$ 


\section{MÖBELSTÜCKE DER ESTERHÁZYS IM MODELLANGEBOT DER FIRMA FRIEDRICH OTTO SCHMIDT}

Einen unmittelbaren Nutzen brachten die Aufträge aus dem Schloss Esterházy, indem die Firma Schmidt ihr Modellangebot erweitern konnte. Die am Mobiliar ausgeführten Restaurierungsarbeiten bezogen sich nämlich vorwiegend auf die Verfertigung von Zusätzen zu den vorhandenen Originalmöbelstücken. Im Zuge dessen wurden Gipsabdrücke von den einzelnen Gegenständen wie Kaminen, Öfen, holzgeschnitzten und aus Bronze verfertigten Motiven, Statuen usw. gemacht und unter ihrer Verwendung oder auch freier Kontaminierung Kopien hergestellt.

Im Liszt-Ferenc-Museum in Sopron befinden sich mehrere Lehnstühle, unter denen (den Inventarnummern zufolge) viele sicherlich und andere wiederum mit großer Wahrscheinlichkeit als Kopien anzusehen sind, die Schmidt im Schloss von Eszterháza verfertigte. ${ }^{19}$ In der gegenwärtigen Ausstellung des Schlosses sind drei Stücke der als Armstuhlvariante verfertigten Lehnstühle mit ovaler Lehne aus Sopron zur Schau gestellt, die die Nationalverwaltung für Denkmäler aus dem Kunsthandel wieder erworben hat. ${ }^{20}$ Die im Nádasdy-Ferenc-Museum von Sárvár aufbewahrte ${ }^{21}$ und den Übergang vom Rokoko zum Louis-XVI.-Stil repräsentierende Kommode mit Bronzebeschlag, Marmorplatte und zwei Schubladen ist höchstwahrscheinlich identisch mit dem Möbelstück, das nicht nur im Aquarell, das Béla Vidovszky vom Eckzimmer des fürstlichen Appartements im Erdgeschoss äußerst detailreich malte, sondern auch auf einer Archivaufnahme von den Möbelstücken des Schlosses Esterházy zu sehen ist. ${ }^{22}$ Eine Fotografie des Möbelstücks ging in den Bestand des Schmidt-Archivs in Wien über. Dass die Aufnahme nicht in einem eingerichteten Interieur, sondern im Werkstattmilieu angefertigt wurde, weist darauf hin, dass das Möbelstück aus dem Schloss von Eszterháza, das selbst vielleicht eine von der Firma produzierte Reproduktion war, für weitere Auftraggeber kopiert wurde (Abb. 1-2).

Das sog. Marie-Antoinette-Schreibtischchen gehörte zu den äußerst bezeichnenden und von den Schmidts am häufigsten kopierten Möbelstücken. Dieses hatte eine unregelmäßig elliptische Tischplatte und mit Bronzebeschlag ver- zierte gebogene Beine. In die Tischkante wurde ein Federmechanismus eingebaut, wodurch der hintere Teil, der mit einer halben Platte verdeckt war, hochgezogen und aus dem Salontischchen ein Damenschreibtisch gemacht werden konnte. In diesem hinteren Teil wurden Schubladen versteckt, die über eine mit Marketerie verzierte Vorderplatte verfügten. Die Platte des vorderen Teils war nach vorne abklappbar und die Deckplatten darunter konnten auf beide Seiten hin geöffnet werden. Unter diesen Deckplatten befanden sich die Geheimfächer; auf einen Knopfdruck sprang auch ein kleines Kästchen hervor. Das Möbelstück war auf seiner gesamten Oberfläche reichlich mit Marketerie verziert. Das Tischchen - bei den Schmidts als Denizot-Modell inventarisiert - wurde viele Jahre hindurch in zahlreichen

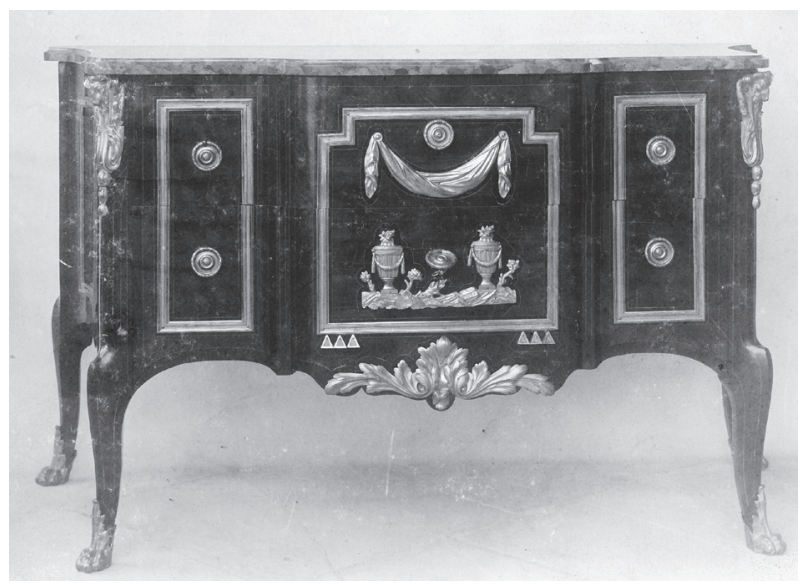

Abb. 1. Foto einer Kommode im Esterházyschloss von Fertőd. 1894 (IM, Archiv, FLT 5768)

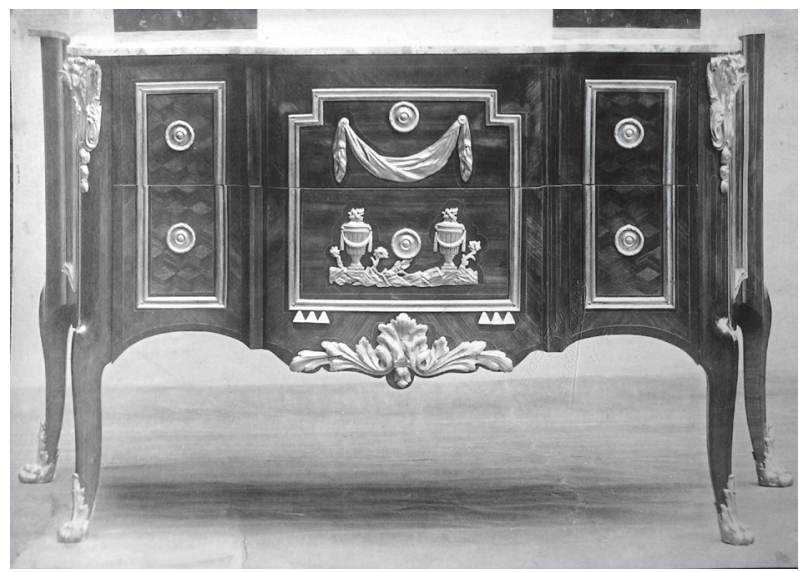

Abb. 2. Foto der Kopie der Kommode des Schlosses von Fertőd (Schmidt-Archiv, Wien) 


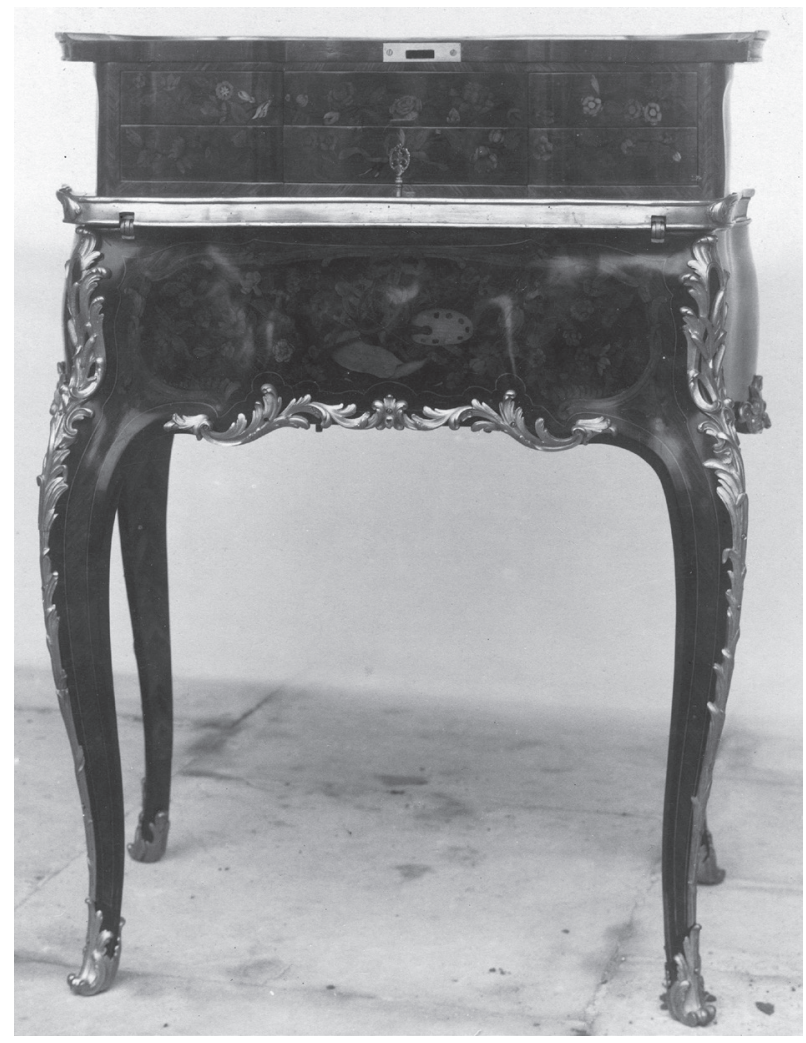

Abb. 3. Foto von einem Damenschreibtisch von Pierre Denizot im Esterházyschloss von Fertőd, 1894 (IM, Archiv, FLT 5735)

Exemplaren kopiert. $^{23}$ Ein Originalexemplar und seine Kopie, in die man keinen Federmechanismus einbauen ließ, wurden anlässlich der Winterausstellung 1898 im sog. Esterházy-Saal des Museums für Kunst und Industrie in Wien ausgestellt. ${ }^{24}$ Die ohne eingebauten Mechanismus hergestellte Kopievariante, bei der sich der Schreibtischaufsatz nicht hochziehen ließ, wurde als Salontisch verwendet. Wir kennen auch weitere Kopien, bei denen entweder die Marketerie oder der Bronzebeschlag fehlten. ${ }^{25}$ Dadurch konnte ein kleines Ziermöbel als Ausstattungs-

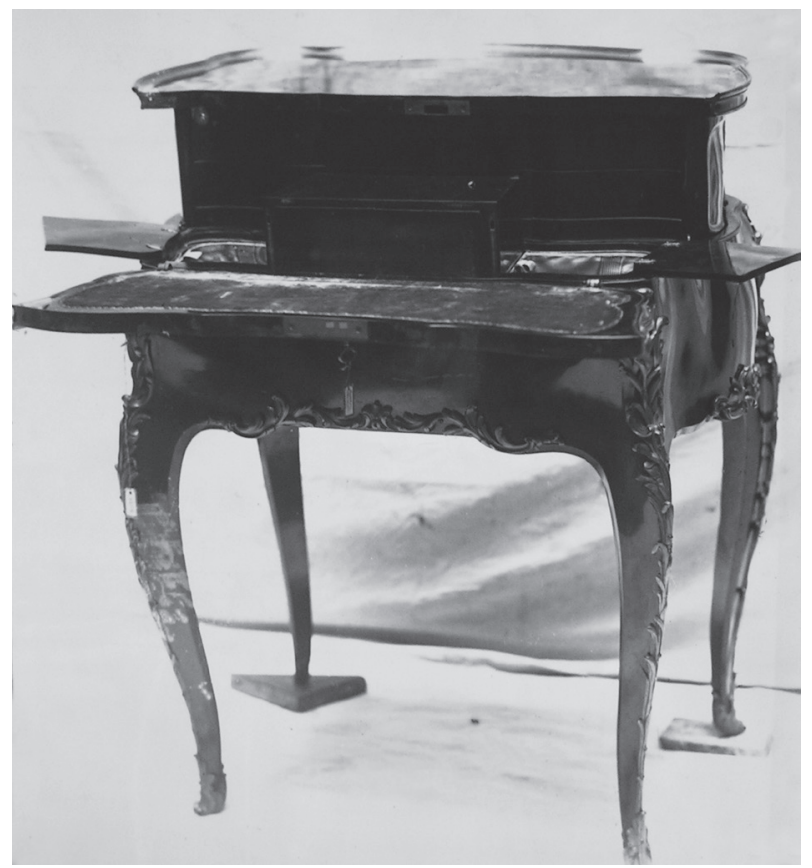

Abb. 4. Foto von einem Damenschreibtisch nach Pierre Denizot, alte Aufnahme (Schmidt-Archiv, Wien)

zusatz in unterschiedlichen Interieurs und zu unterschiedlichen Preisen aufgestellt werden (Abb. 3-4).

Jenő Radisics, der sowohl den Möbelbestand des Schlosses Pálffy in Királyfa als auch jenen des Schlosses in Eszterháza einzeln durchmustern durfte, brachte im Fall von drei Möbelstücken der Pálffys auf den Inventurbogen folgende Anmerkung an: „Kopie, deren Original sich im Schloss Esterházy befindet.“26 An einem der Bögen merkte Radisics nachträglich an: „Verfertigt von Otto Friedrich Schmidt [sic!] in B[uda]pest." Dieses Stück lässt sich aufgrund der detaillierten Beschreibung, die der Direktor des Museums für Angewandte Kunst gab, als das erwähnte MarieAntoinette-Schreibtischchen, das mit einem Federmechanismus versehen wurde, identifizieren. ${ }^{27}$

\section{DER WIDERHALL DER SCHLOSSRESTAURIERUNG VOM SCHLOSS ESTERHÁZY IN UNGARN}

Der mittelbare Nutzen der für die Zwangsverwaltung der Esterházys ausgeführten Restaurierungsarbeiten war, dass sie der Firma Schmidt maßgeblich zur landesweiten Bekanntheit in Österreich und Ungarn verhalfen.

Max Schmidt berichtete dem Bischof Bubics am 21. September 1896, dass der Markgraf
Pallavicini und seine Gattin bzw. die Gräfinnen Károlyi und Széchenyi einen Besuch in Eszterháza abstatteten und nicht nur ihrer Anerkennung angesichts der Schönheit des Schlosses Ausdruck gaben, sondern auch nach der Adresse der Firma Friedrich Otto Schmidt fragten. ${ }^{28}$ Aus den Geschäftsbüchern, die im Nachlass 
der Schmidts in Kiscell aufbewahrt sind, geht deutlich hervor, dass um die Jahrhundertwende und in den nachfolgenden Jahren die Familien Károlyi und Széchenyi zu den größten Auftraggebern der Firma zählten. Als die Schmidts 1903 bei der fürstlichen Familie Liechtenstein einen Antrag auf Kopiererlaubnis stellten, erinnerte einer der Familienmitglieder einen anderen Familienangehörigen an die Gebrüder Schmidt mit folgenden Worten: ,Wie du weist sind die Brüder Schmidt ungewöhnlich strebsame, kunstsinnige und geschmackvolle Leute. Ihr Vater und sie selbst haben durch dreissig Jahre [sic!] das Schloss Esterhász bei Ödenburg im Auftrage des Fürsten Estherhaszy restaurirt [...].".29

Der von den Esterházys erteilte Auftrag und die Beziehungen zu Zsigmond Bubics, der in Historikerkreisen und im Umfeld der Kunstgewerbe eine wichtige Rolle spielte, waren neben dem Aufbau von unmittelbaren Kundenkontakten auch deshalb von Bedeutung, weil die Firma dadurch einen Anschluss an kunstgewerbliche Ausstellungsaktivitäten in Ungarn fand und 1898 auf österreichische Ausstellungen zum Kunstgewerbe zurückkehren konnte. Nicht zuletzt waren die Restaurierungsarbeiten auch aus dem Grunde von zentraler Bedeutung, weil Schmidt dadurch und durch sein wachsendes Prestige als registrierter Handwerker ein Geschäft im Haus Nr. 32 auf dem Leopold-Ring eröffnen konnte. ${ }^{30}$ Die umfangreichen und vielschichtigen Arbeiten, die für die gewichtigste ungarische Aristokratenfamilie ausgeführt wurden, gewährten eine ausgezeichnete Referenz für die Firma. Wie dies auch in der Praxis eine große Bedeutung erlangen konnte, machen die Zeilen von Hugo Schmidt deutlich, die er dem Zentraldirektor des Majorats, József Haller, am 23. Juli 1898, d. h. zu Beginn der groß angelegten Restaurierungsarbeiten am Palais Esterházy in Ofen, zukommen ließ. ${ }^{31}$ In Bezug auf die geplante Sanierung beteuerte der Prokurist, die bestmögliche Leistung zu erbringen. Da die Firma ihrem Grundprinzip nach nur die Zufriedenheit des Kunden als Hauptkriterium anerkenne, würde sie jegliche Möbelstücke, die diese Anforderung nicht erfüllen, zu Vollpreis zurückkaufen. ${ }^{32}$ Die Firma würde insbesondere die Innenausstattung des Herzogspalais beachten: ,[D]a sich in Pest bei dem ganzen Hochadel grosse Erwartungen an diese Arbeit knüpfen, werde ich größte Anstren- gungen machen, die fürstlichen Herrschaften vollauf zufrieden zu stellen. ${ }^{633}$

Die ersten Nachrichten von der groß angelegten Schlossrenovierung in Fertőd verbreiteten sich dank der Zimmerreihe der Esterházys, die in der Millenniumsausstellung zu sehen war. Wie bereits erwähnt, kam die Idee von der historischen Interieursreihe zum ersten Mal im Jahr 1893 während der Vorbereitungen zur Millenniumsausstellung auf. Der Grundidee nach sollten dem Publikum gewisse Knotenpunkte der ungarischen Geschichte durch historische Gegenstände oder deren Kopien in Interieursgruppierungen veranschaulicht werden. ${ }^{34}$ Dieser Vorstellung schloss sich als Erster Bischof Bubics an, der in der Kommission der kirchengeschichtlichen Untergruppe tätig war; er war es auch, der beim Fürsten Pál Esterházy erreichen konnte, die Kopien von bestimmten Zimmern des Schlosses auszustellen. Der Fürst war sogar bereit, die Herstellungskosten der Reproduktionen zu übernehmen. ${ }^{35}$

Die Zimmerreihe der Esterházys wurde im Geschoss des nordöstlichen Traktes des sog. Renaissanceflügels untergebracht, der einen Teil der von Ignác Alpár entworfenen historischen Baugruppe darstellte. Aus dem achteckigen Saal des nördlichen Eckpavillons, in dem Porträts von Offizieren aus der Familie Esterházy, das Bild des Generals Károly Esterházy, eine vergoldete Kutsche sowie sechs Armstühle mit gesticktem Gewebe ausgestellt wurden, gelangte man zum Vorraum, der eine Paraphrase eines Teils der Sala terrena in Fertőd darstellte (Abb. 5). Von hier konnte der Besucher durch zwei Türen weitergehen: Die rechte Tür ging auf eine Flur mit vier Eingängen auf der linken Seite, die zu vier Sälen führten (Abb. 6). Diese Säle konnten auch unmittelbar aus der Sala terrena, durch die linke Tür erreicht werden. Im Spiegel an der Abschlusswand des letzten Saales erblickte somit der Besucher, wenn er mit seinen Augen den Saal durch die nacheinander geordneten Türe der Raumreihe durchschweifte, eine unendlich vervielfachte Enfilade.

Der erste Raum nach der Sala terrena war ein Zimmer, das mit Jagdszenen präsentierenden Tafeln dekoriert war und in dem Stühle mit grünem Seidenbrokat aufgestellt wurden (Abb. 7). ${ }^{36}$ Dieses Zimmer imitierte zwar mit seinen Reproduktionstafeln von Jagdszenen den 


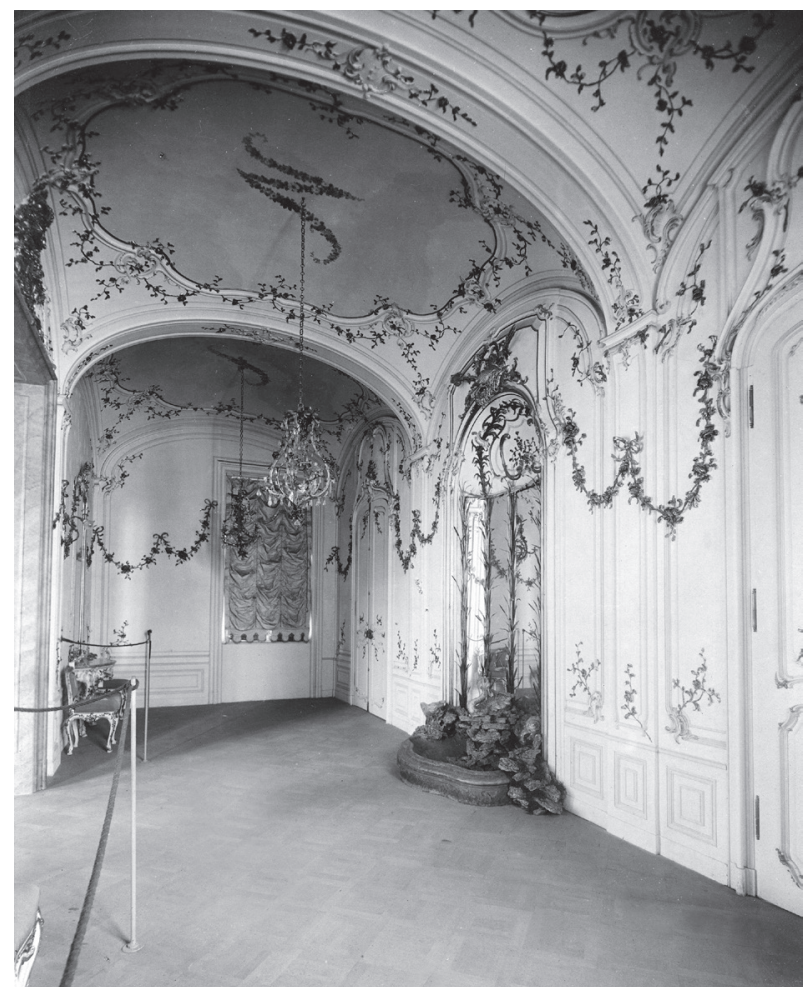

Abb. 5. „Sala terrena" in der Esterházy-Zimmerreihe im Renaissance-Gebäude der Millenniumsausstellung von 1896 (Aufnahme von Antal Weinwurm, IM, Archiv, FLT 4958)

Jagdsaal (oder auch grünen Saal), der sich auf dem ersten Stock neben dem Festsaal des Corps de Logis im Schloss von Eszterháza befand, doch im Gegensatz zum Original wurde die Wand zwischen den Fenstern mit Spiegeln und Konsolen dekoriert. Die Sitzmöbel erhielten einen Bezug aus grün-goldenem Seidenrips. Auf der kürzeren Raumseite mit den Fenstern stand ein geschnitzter Konsolentisch aus Holz mit Marmorplatte; über ihm hing ein Spiegel. Auf der Langseite war eine Barockkommode mit zwei Schubladen und Marmorplatte zu sehen, auf der eine barocke Kaminuhr und zwei Altwiener Porzellanvasen ausgestellt wurden. ${ }^{37}$

Aus diesem Zimmer gelangte man in einen Salon, auch Prunksaal genannt, in dem die zwei gegenüberliegenden Wände mit jeweils einem Figurenporträt von Karl III. (VI.) und Maria Theresia dekoriert wurden (Abb. 8). Die Sitzmöbel in diesem Raum entsprachen jenen im Nachbarzimmer, die Bezüge waren jedoch in Gold und Blau gehalten. In der Ecke an der Fensterseite standen klassizistische Konsolentische, auf deren Marmorplatten mit Schachbrettmustereinlagen japanische Vasen aufgestellt

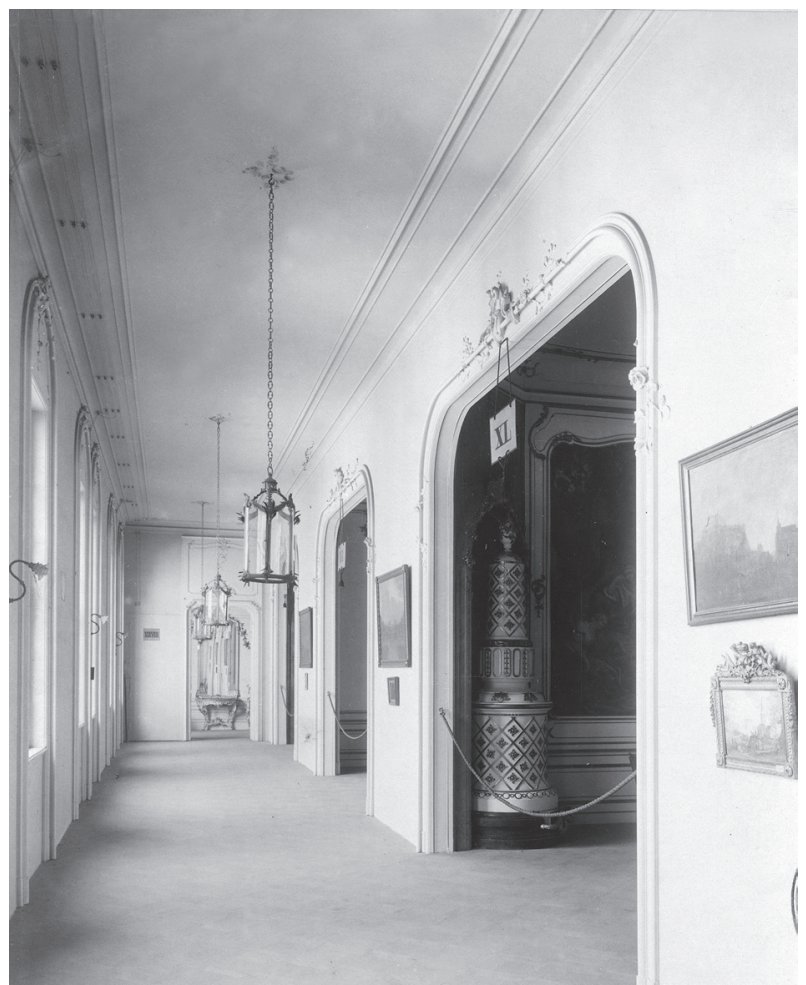

Abb. 6. Flur neben der Esterházy-Zimmerreihe im Renaissance-Gebäude der Millenniumsausstellung von 1896 (Aufnahme von Antal Weinwurm, IM, Archiv, FLT 4959)

wurden. Dieses Zimmer war keine unmittelbare Imitation der Zimmer in Eszterháza, sondern ahmte lediglich die Supraporte- und Boiserieverzierung der repräsentativen Zimmerreihe im ersten Stock nach. 38

Der nächste Raum stellte eine Paraphrase des Maria-Theresia-Zimmers, d. h. des südöstlichen Eckzimmers im ersten Stock des Mittelflügels in Eszterháza, dar (Abb. 9). Das rot tapezierte Baldachinbett, das dem Saal seine Grundfarbe gab, folgte dem Original nur in seiner Form, doch die Boiseriemotive galten als beinahe genaue Abbildungen; eine Kopie des Gobelins hinter dem Bett kam ebenfalls ins Zimmer in die Burg Vajdahunyad. Doch das Mobiliar - vor allem der Konsolentisch zwischen den Fenstern und der Spiegel darüber - wurde im Gegensatz zu Eszterháza nicht im Stil Ludwigs XVI., sondern im Rokokostil verfertigt. Der Grund dafür war offensichtlich, dass die Möbelstücke mit dem Musik spielenden und ebenfalls rot tapezierten Thron übereinstimmen sollten. Ein wesentlicher Unterschied zum Original war, dass im Saal der Millenniumsausstellung lediglich ein Gobelin ins Boiseriefeld angebracht wurde, während das 


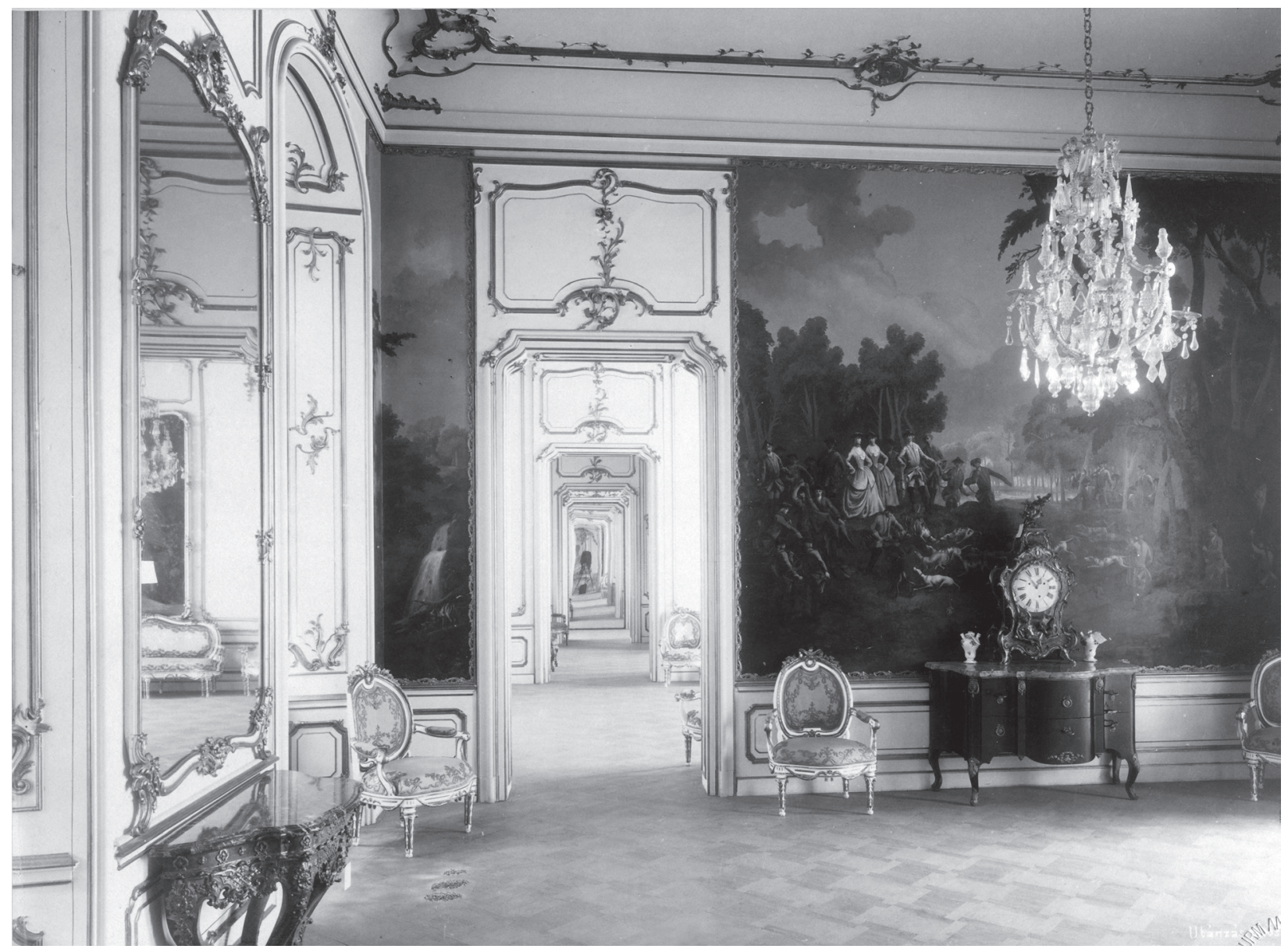

Abb. 7. Jagdsaal in der Esterházy-Zimmerreihe im Renaissance-Gebäude der Millenniumsausstellung von 1896 (Aufnahme von Antal Weinwurm, IM, Archiv, FLT 4960

Eckschlafzimmer in Eszterháza mit seinen Gobelins und Gobelindetails, die in den Ecken und auf der gesamten Täfelung zu sehen waren, eine viel intimere und wärmere Wirkung erzielte.

Die letzte Räumlichkeit hinter dem Schlafzimmer war das sog. Vieux-Laque-Zimmer oder auch Pfeifenzimmer: Hier wurde das sog. indische Kabinett mit seinen japanischen Lacktafeln, das sich im Eszterházaer Fürstenappartement im Erdgeschoss befand, in freier Interpretation beschworen. ${ }^{39}$ An die Wände des Flurs entlang der Räume wurden nicht nur Kopien von jenen vier Gemälden mit dem Bild des Schlosses von Eszterháza aufgehängt, die 1780 von Gaetano Pesci aus unterschiedlichen Blickwinkeln gemalt wurden, sondern auch eine Vedute von Pozsony.

Die in der Millenniumsausstellung präsentierte Zimmerreihe der Esterházys verstärkte die habsburgertreue Ausrichtung des Renaissanceteils der historischen Gruppe. Die hofseitige Fassade der architektonischen Kompilation von
Ignác Alpár hatte zwischen den beiden Eckpavillons eine konkave Bogenformung und in der Mitte eine Kuppel als Krönung. Das Vorbild für die Massenanordnung und die Eckkuppeln war zugegebenermaßen die von Fischer von Erlach entworfene, unabgeschlossene Architektur der Winterreitschule in der Wiener Hofburg, ${ }^{40}$ die gerade um die Jahrhundertwende um den Ausbau des sog. Michaelertraktes, wie dies im Originalplan vorgesehen war, ergänzt wurde. ${ }^{41}$ In diesen Teil der Baugruppe der Millenniumsausstellung kamen die Zimmerkopien aus dem soeben renovierten Fertőder Schloss der kaisertreuen Familie Esterházy. Der Saalreihe folgte ein bogenförmige Flurabschnitt, auf dem Denkmäler der Zeit von Rákóczi und Thököly zu sehen waren, dann eine Porträthalle mit den Bildnissen der Herrscher aus dem Haus Habsburg und ein Saal, in dem Denkmäler aus der Maria-Theresia-Zeit sowie aus der Zeit des Adelsaufstandes im Jahre 1809 ausgestellt wurden. Der Besucher 


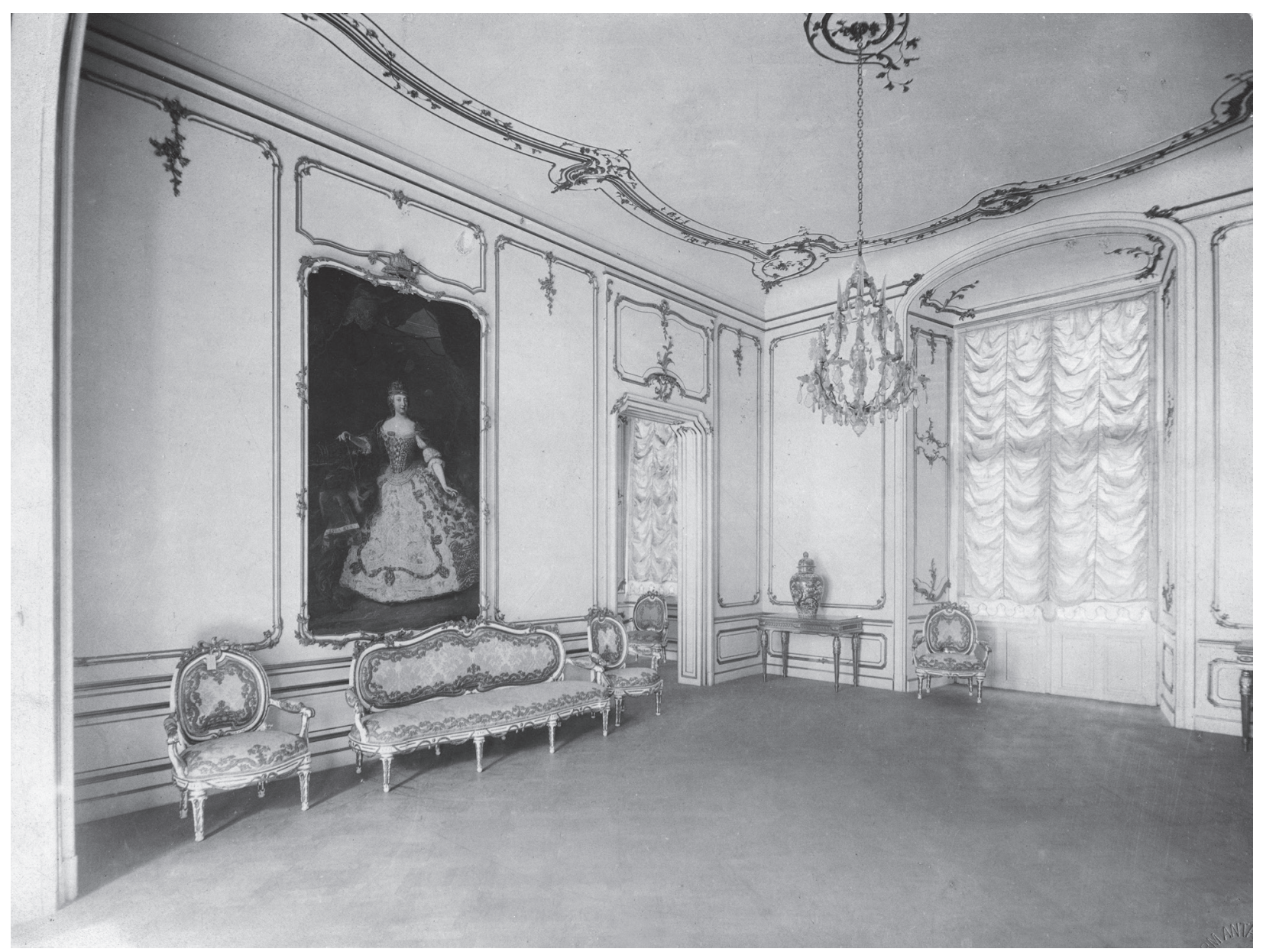

Abb. 8. Salon neben der Esterházy-Zimmerreihe im Renaissance-Gebäude der Millenniumsausstellung von 1896 (Aufnahme von Antal Weinwurm, IM, Archiv, FLT 4459)

gelangte schließlich zur Schau der Reliquien aus den Jahren 1848-1849. Die Schaukelpolitik des Millenniumszeitalters kam in diesem Teil der historischen Hauptgruppe mit einer etwas lächerlichen Folgerichtigkeit zum Ausdruck.

$*$

In den Raumbeschreibungen wurde stets betont, dass die Interieurs von Eszterháza nicht als organischer Teil der Geschichte der ungarischen Kunst anzusehen wären. Kamill Fittler, der Direktor der Kunstgewerbeschule meinte: „[... D ]er Gesamtgeist dieses für einen ungarischen Aristokraten gebauten Appartements ist fremdartig; der Konstrukteur ist ein Fremder, seine Mitarbeiter sind Fremde. Die Kunst, die sich in ihm äußert, ist bei Weitem nicht erstrangig, doch ist sie vornehm; seine Möblierung ist geschmackvoll. “" Jenő Radisics entwickelte sogar eine komplexe Theorie über die Bewertung der Rokokointerieurs in Eszterháza. Demnach soll der Universalstil des 18. Jahrhunderts auf die durchschnittliche ungarische Architektur kaum einen Einfluss ausgeübt haben: , „... I $]$ n den Herrenhäusern der Provinz blieb alles beim Alten, abgesehen vom Dach und manchen Äußerlichkeiten, die die Architektur landesweit okkupierten. ${ }^{643}$ Im Gegensatz dazu hätte die Aristokratie die ausländische Mode übernommen, die dementsprechend nichts anderes gewesen sei als „ein okkupierendes Fremdelement, das uns bruchlos und schlagartig in die betörende und raffinierte Kultur des 18. Jahrhunderts einführt und diese den uralten Traditionen gegenüberstellt". Im Abschluss der Beschreibung der Zimmer ist Folgendes zu lesen: „Aus den beigelegten Abbildungen kann sich jeder ein Bild von den soeben flüchtig beschriebenen Räumen machen. Wir haben dazu hinsichtlich des einheimischen Kunstgewerbes nichts hinzuzufügen. Der Stil war ein fremder, eingewanderter Ankömmling, der 


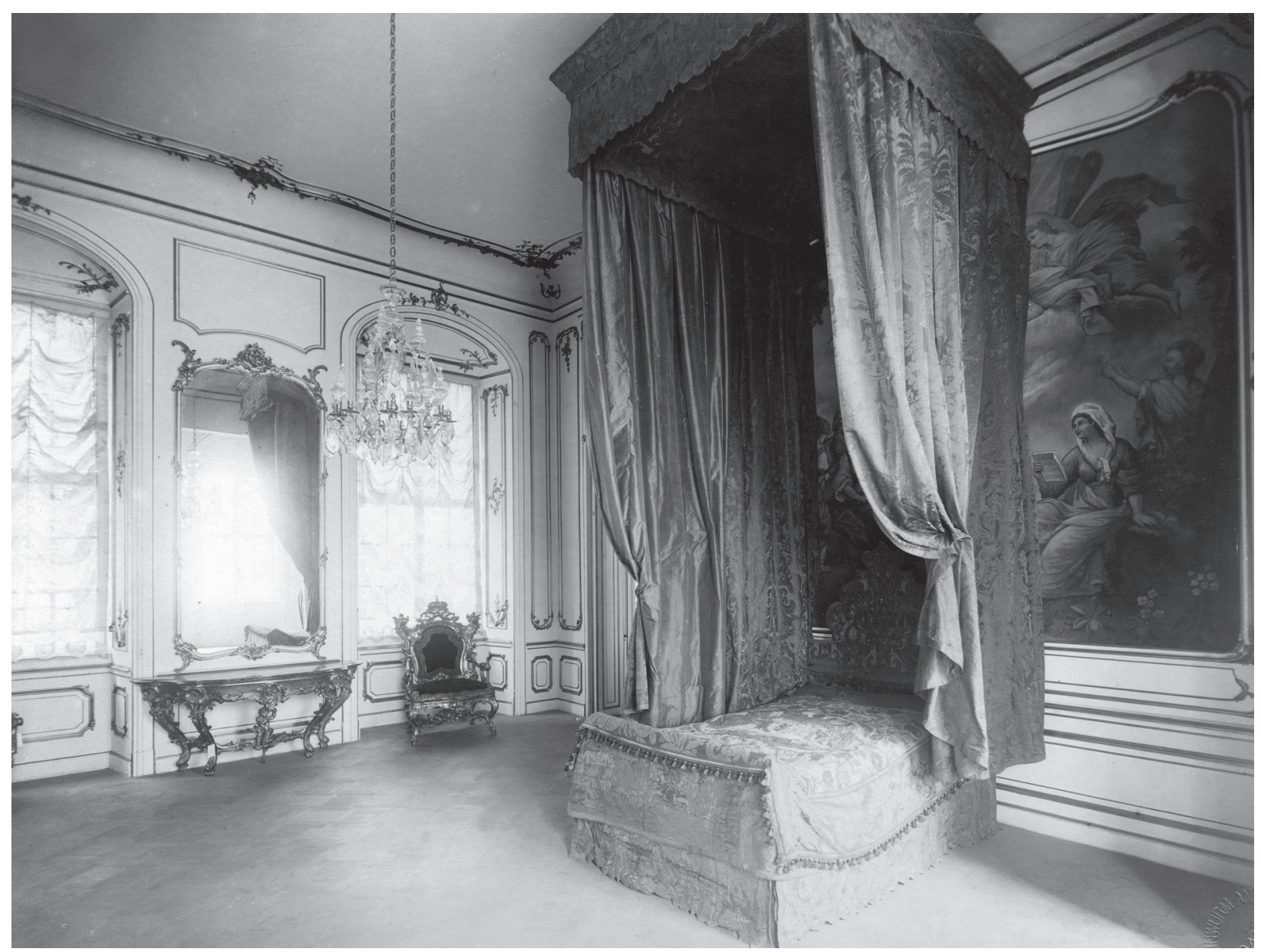

Abb. 9. Schlafsaal in der Esterházy-Zimmerreihe im Renaissance-Gebäude der Millenniumsausstellung von 1896 (Aufnahme von Antal Weinwurm, IM, Archiv, FLT 4961)

unsere Sprache nicht sprach und dessen Sprache die Nation nicht verstand." Radisics schloss seine Beschreibung mit einem stark nationalistisch anmutenden historischen Entwicklungs-, besser gesagt Verkümmerungskonzept ab, indem er den Angelpunkt gerade im Rokoko des 18. Jahrhunderts - und in seinem hervorragendsten Vertreter in Ungarn, dem Schloss Esterházy - zu erblicken meinte: „,... D ] er neue Stil tötete unseren eigenen Geschmack, der auf unseren Traditionen beruhte, ohne die Kraft zu anderweitigen Tätigkeiten zu verleihen. Mit seinem betörenden Zauber schuf er eine gähnende Kluft zwischen der Vergangenheit und der damaligen Gegenwart. Was einmal war, konnte nicht mehr gefallen, und da die einheimischen Kräfte nicht imstande waren, die veränderten Ansprüche zu befriedigen, konnte sich von diesem Zeitpunkt an das Ausland bei uns einnisten [...]." ${ }^{64}$

Die zitierten Ausführungen sind deshalb lehrreich, weil sie eine Erklärung dafür abge- ben, warum Radisics die Zustimmung verweigerte, die Zimmerkopien zum Teil der ständigen Ausstellung im Museum für Angewandte Kunst zu machen. Die Aufstellung im Museum war eine Idee des Direktors der historischen Hauptgruppe, Imre Szalay. Am 18. November 1896, fünf Tage vor dem Abbau der Ausstellung wandte er sich brieflich mit der Bitte an Bubics, beim Fürsten Esterházy zu bewirken, die Zimmer dem Museum zur Verfügung zu stellen. ${ }^{45}$ Der Zentralverwalter des Majorats der Esterházys, József Haller, informierte Bubics am 31. Dezember 1896, dass er sich mit der Frage an den Fürsten gewandt hatte, ob es ihm erlaubt sei, ,auf die Höchstempfehlung“" von Bubics „die fraglichen Gegenstände dem Gewerbemuseum“" zu geben. Fürst Pál soll laut Haller seine Zustimmung mit Freude gegeben und geäußert haben, „dass ,er dies gern auf den Altar der Heimat stellt ${ }^{6}$ - und er rief mich sofort, die Meldung als Fernschreiben aufzusetzen". ${ }^{46}$ Der Leiter 
der Zwangsverwaltung schrieb noch am gleichen Tag das Museum für Angewandte Kunst und die historische Hauptgruppe an: Fürst Paul sei bereit, die Lamperie, den Fußboden, die Türe, Spiegel usw. in einem Gesamtwert von 15000 Forint (aber ohne Möbel) dem Museum zu schenken. ${ }^{47}$

Radisics bedankte sich für das Geschenk beim Fürsten am 27. Januar 1897 und beauftragte zugleich Győző Czigler, Ignác Alpár und Max Schmidt, eine Untersuchung vor Ort durchzuführen, ob die Räume abgebaut und transportiert werden können. ${ }^{48}$ Schmidt nahm an der Besichtigung am 2. Februar mit Hinweis auf seine Erkrankung nicht teil, aber er setzte den Direktor brieflich in Kenntnis, dass die Wände und die Decken nicht in ihre Elemente zerlegt werden können. Auch Alpár und Czigler behaupteten, dass die Wände nicht transportierbar seien, da sie aus auf Holzgerüst fixiertem Drahtgewebe und Gipsputz bestünden. Würden sie zerlegt werden, hieß es, würde ihr Wiederaufbau etwa die gleichen Kosten wie die ursprüngliche Aufstellung verursachen. Radisics unterbreitete demnach Gyula Wlassics, dem Minister für Kultus und Unterricht, drei mögliche Lösungen: Entweder werden die Türen, die Holztäfelung, die Spiegel, der Fußboden und die Holzöfen entfernt oder die Wände werden zersägt und im Museum wieder zusammengestellt oder eben die gesamte Zimmerreihe auf ihrem jetzigen Ort belassen. Die Argumente, die der Direktor gegen die erste Version einbrachte, brachten unwillkürlich seinen Widerwillen gegen die gesamte Zimmerreihe zum Ausdruck. Er meinte, einen Wert würde nur das Gesamtinterieur besitzen, nicht aber die einzelnen Elemente an sich: „[... D $]$ ie Wandverkleidung an sich ist kein Kunstgegenstand, und da die Türen, die Rahmen keine treuen Nachahmungen der Originale sind, können sie auch nicht als Dokumente angesehen werden. Und gegen die Ausstellung der Holzkopien der Fayenceöfen muss ich entschieden Stellung nehmen, da derartige Nachahmungen nur das Niveau des Museums verringern würden; wenn ich also die Teile, die entfernt werden können, abholen ließe, würde ich eigentlich den Zimmern einen Schaden zufügen und der Institution gar keinen Nutzen bringen. " Die zweite Version lehnte
Radisics wegen ihre Kostspieligkeit ab und schlug somit die dritte Variante vor, nämlich die Zimmer vor Ort zu behalten, d. h. sie in das bereits zu diesem Zeitpunkt geplanten Museum für Landwirtschaft zu integrieren, allerdings mit dem Eigentumsvorbehalt des Museums für Angewandte Kunst. ${ }^{49}$ Am 18. März erteilte das Ministerium eine Zusage. ${ }^{50}$

Im Sommer 1897 brachte das Ministerium für Kultus und Unterricht einen Antrag beim Landwirtschaftsminister ein, der zufolge die Zimmerreihe entsprechende Aufschriften erhalten sollte, denen sowohl die Person des Spenders wie auch die Institution als Besitzer zu entnehmen waren. ${ }^{51}$ Etwa zwei Jahre lang, ab September 1897 bis September 1899, wurden die Zimmer als Bibliothek und Leseraum des Museums für Landwirtschaft benutzt. ${ }^{52}$

Zur Zerlegung der Zimmerreihe und ihrem Abtransport ins Museum für Angewandte Kunst kam es dann im Herbst 1899. ${ }^{53}$ Das weitere Schicksal der Elemente ist recht undeutlich. Keine der eingelangten Gegenstände wurde in einer Ausstellung zur Schau gestellt und lediglich eine Doppeltür, die zur Kopie der ehemaligen Sala terrena führte, wurde in den Vorraum der Bibliothek im ersten Stock integriert. Sie ist bis heute dort zu sehen.

Im Winter 1896-1897 hätte Radisics noch die Möglichkeit gehabt, alles Mögliche in das völlig leere Gebäude des Museums einbauen zu lassen. In der Geschichte des Museums kam es ja seit der Eröffnung mehrmals vor, dass gesamte Interieurs im Gebäude aufgestellt wurden. Wie einige schlichte Bemerkungen im zitierten Briefwechsel von Radisics bezeugen, basierte sein Widerstand nicht nur auf seinen nationalistischen Ressentiments, sondern auch auf seiner Distanzierung von den ungenauen Kopien, die letztendlich einen prinzipiellen Einwand bedeutete. Deshalb wurde das 1899 unwillig übernommene Material der Millenniumsausstellung ins Lager geschafft, bis der Leiter der Möbelabteilung des Museums, Ferenc Batári, 1976 dem Schloss von Fertőd einige Elemente übergab, die weder durch Vermessung noch durch eine Liste oder Fotografien dokumentiert wurden. Im Schloss wurden diese Elemente - ebenfalls undokumentiert - teils eingebaut, teils gelagert und sind heute noch irgendwo in Lagern zu finden. ${ }^{54}$ 


\section{DIE WINTERAUSSTELLUNG 1898 IM WIENER KUNSTGEWERBEMUSEUM}

In der im November 1898 eröffneten Winterausstellung konnte das Publikum im k. k. Österreichischen Museum für Kunst und Industrie sowohl Kopien von historischen Möbelstücken als auch modernes Mobiliar besichtigen. Ein guter Teil der Kopien wurde anhand von Originalen aus dem Besitz von Aristokraten verfertigt: Graf Vinzenz Latour, Graf Ödön Batthány-Strattmann und Baron Albert Rotschild stellten den Wiener Handwerkern Gegenstände aus Silber und Möbelstücke zur Verfügung. ${ }^{55}$ Die eigentliche Sensation der Ausstellung war die neue, im Rokokostil erfolgte Ausstattung des Sitzungssaals des Museums, die eine sozusagen detailtreue Kopie des Festsaals aus dem Schloss in Fertőd darstellte (Abb. 10).

In der Budapester Millenniumsausstellung von 1896 konnte die Reproduktion des Fertőder Festsaals, der anhand seines Deckenfreskos auch Apollosaal genannt wurde, vermutlich wegen Platz- und Geldmangel nicht in Angriff genommen werden. ${ }^{56}$ Die Zimmerreihe der Esterházys kam in der Budapester Ausstellung, wie bereits erwähnt, in jenen Flügel des sog. RenaissanceGebäudes im Stil von Fischer von Erlach, der durch die Saalreihe an der gegenüberliegenden Seite mit den auf die Thököly- und Rákóczi-Zeit hinweisenden Reliquien ausgeglichen wurde.

In österreichischem Kontext repräsentierte der Saal natürlich jenen Barockstil aus der Zeit von Maria Theresia, der bereits ab den 1880er Jahren und am Ende der 1890er eindeutig den österreichischen Nationalstil darstellte. ${ }^{57}$ Das von Arthur von Scala geleitete Museum wurde nach der ersten Winterausstellung von 1897 u. a. der Zurückdrängung der einheimischen Traditionen durch englische Importgegenstände beschuldigt, d. h. der Propagierung von englischen historischen und zeitgenössischen Möbelstücken gegenüber der geläufigen Wiener Modelle. Nach 1898 erfolgte dann auch die spektakuläre Behebung des Mangels an Nationalcharakter. ${ }^{58}$

Der Prunksaal der Firma Schmidt wurde in dem Pressematerial, das das Museum den Tageszeitungen zur Verfügung stellte, als genaue Kopie des Festsaals des Schlosses Esterházy bezeichnet. ${ }^{59}$ Diese Beschreibung im Umfang von einer Seite berichtet, dass aus den mehr als zweihundert Räumen des Schlosses in Eszterháza, das eine halbe Stunde von Sopron entfernt liegt, mindestens hundert Gemächer außerordentlich interessante Stuckarbeiten aufzuweisen hätten. Der durch die Firma Friedrich Otto Schmidt ausgestellte Saal sei eine verkleinerte Kopie des Festsaals des Schlosses, der „unter allen Umständen von italienischen Künstlern ausgeführt" wurde. Die Firma hätte sieben Jahre lang das Schloss für fast eine Million Forint renoviert und für die Erneuerung des Festsaals jene Zeichnung verwendet, die man in einer alten Rumpelkammer fand. Dem Bericht zufolge sei der im Saal ausgestellte Gobelin 1781 in der königlichen Gobelinmanufaktur nach den Plänen von François Ménageot verfertigt worden. Im Text wird betont, dass der Bilderteppich deshalb so interessant sei, weil er noch vor „der gewaltigen Erschütterung ${ }^{6}$ der französischen Revolution, die die Manufaktur zum Abbrechen ihrer Produktion veranlasste, hergestellt worden war. Ein Teil des Mobiliars sei nach den Originalstücken in Eszterháza, ein anderer nach französischen Möbeln aus der zweiten Hälfte des 18. Jahrhunderts entworfen worden.

Ludwig Hevesi, der das Pressematerial beinahe wortwörtlich übernahm, nannte den Saal ein „Prachtstück" der Ausstellung, und auch Josef Folnesics bezeichnete ihn als „Bijou “ ${ }^{60}$ Folnesics bekräftigte die Legitimation der genauen Kopie und ihrer Ausstellung mit dem Argument, dass die historischen Stile tot seien und jegliche Weiterentwicklung, d. h. jeglicher Versuch zu ihrer Wiederbelebung nur noch ein Mischwesen, also einen weder toten noch lebendigen Stil, ergeben würde. Im Gegensatz dazu würde die Reproduktion eines historischen Werkes dem Betrachter, der mit dem Original nicht in Berührung kommen kann, zum Genuss des Originals verhelfen.

In der Zeitschrift des Museum selbst bezeichnete Fritz Minkus den Saal als „die denkbar vollendetste Erfassung alten Kunstgeistes, als technisch geradezu virtuose Leistung", die „die höchste Bewunderung“" verdiene. ${ }^{61}$ Minkus zufolge sei der Saal mit der Ausnahme der Türen (diese waren Kopien der Türen aus dem Palais Schwarzenberg in Wien) eine sozusagen vollkommene Nachbildung des Originals gewesen. Die Museumsdirektion sei zur Ausstellung 


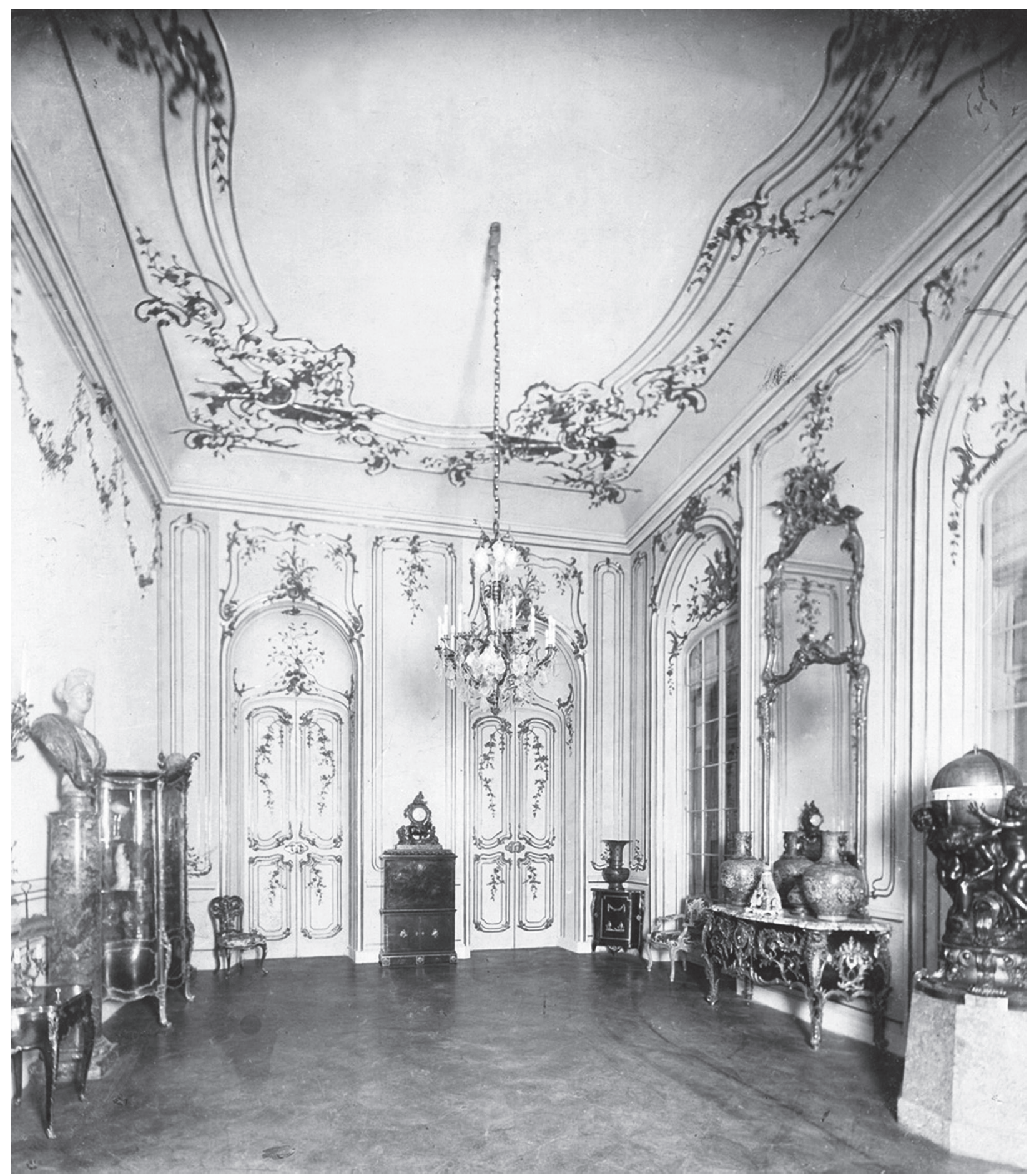

Abb. 10. Esterházy-Raum der Firma Friedrich Otto Schmidt 1898 in der Winterausstellung des k. k. Österreichischen Museums (MAK, Mappe T2-B16-L15.35/C, I.N. 7326/1)

dieser detailtreuen Kopie durch die Einsicht veranlasst worden, dass die gegenwärtige Epoche, die in der streng objektiven historischen Forschung bedeutende Fortschritte erzielt habe, die Forderung stelle, dass wenn man schon kopiert, dies mit „peinlicher $[. .$.$] Treue“ gemacht werde,$ jedenfalls aber „unter Wiedergabe des künstleri- schen Gesamtcharakters der betreffenden Epoche ". ${ }^{62}$ Man dürfe keine vermeintlichen Nachbildungen herstellen, wie dies beispielsweise die Romantik mit der ,angebliche[n], Gotik " tat oder die sechziger Jahre mit dem ,vorgebliche[n] Rokoko“, da diese „weder Nachahmungen noch Neuschaffungen" seien. ${ }^{63}$ Die positivistische 
Einstellung von Minkus war eigentlich mit den Grundsätzen der Wiener kunstgeschichtlichen Schule im Einklang. Ihr gemeinsames Merkmal bestand nicht nur in der „Akribie der Allerkleinsten", auf der hier die exakte Kopie und dort die historische Erkenntnis basierte, sondern auch in dem Bestreben, sich in die Gesinnung der historischen Epochen zu begeben. Für Wickhoff war dies die Einsicht in das geistesgeschichtliche Umfeld, für Riegl die Erforschung des Kunstwollens und für Minkus die Forderung, der historischen Stilepoche in größerem Maße als bisher zu entsprechen. ${ }^{64}$

Der Aufsatz von Minkus erklärt auch die Janusköpfigkeit der von der Firma Friedrich Otto Schmidt ausgestellten Gegenstände: „Der Rokokosaal der Winterausstellung hat manche verbohrte Gegner der modernen Richtung zu dem triumphierenden Hinweis veranlasst, dass, um einen wahrhaft grossartigen, effektvollen Prunkraum zu schaffen, die Innendekoration denn doch immer wieder auf die alleinseligmachenden alten Stile zurückgreifen müsse! Wer das gegen den modernen Stil ins Treffen führt, dem kann man, glaube ich, berechtigt mit dem Citate antworten: ,Was ihn Euch widrig macht, macht mir ihn wert! ${ }^{65}$ Gerade in dem Umstande, dass der moderne Stil nicht, wie alle historischen Stile, zuerst in der Ausstattung von Prunkräumen, sondern im Wohngemach, im Nutzraum auftritt, liegt sein ganzer Wert, liegt die Richtigkeit des Verhältnisses, in dem die Kunst zum Zeitgeiste zu stehen hat, liegt die Gewähr für seine gedeihliche Entwicklung: möge er immerhin vorerst den unpersönlichen Paraderaum, der im heutigen Kulturleben lange nicht mehr die Rolle spielt, die er in verflossenen Jahrhunderten innegehabt, den alten Stilen überlassen! Beschränkt auf das engere Feld des Nutzraumes, der vor allem das Praktische, das Individuelle erheischt, wird er um so festere Wurzeln schlagen, um so zeitgemässer sich entfalten!"66 Der Schmidt'sche EsterházySaal sollte also nicht nur zeigen, wie das authentische Alte sei, sondern paradoxerweise auch, wie das authentische Moderne sei. Er versucht nämlich nicht, ein repräsentatives Interieur zu kreieren, sondern bleibt bei der Ausstattung von funktional gebundenen Räumlichkeiten.

Auch Adolf Loos lenkte die Aufmerksamkeit auf den Umstand, dass die Firma Schmidt den modernsten und den gehobenen alten Stil gleich- zeitig herstelle: nämlich nicht nur die Innenausstattung des neuen Gebäudes der Secession, sondern auch den Esterházy-Saal. „Ist es nicht auffallend, daß die kühnsten Neuerer, also die tüchtigsten Menschen auch die tiefste Verehrung für die Werke ihrer Vorfahren bekunden? Eigentlich nicht. Denn die Tüchtigkeit kann nur wieder von der Tüchtigkeit gewürdigt werden. Das Publicum wird sich erinnern, welches Aufsehen die hochmodernen Möbel eines Wiener Ateliers in der Ausstellung der Secession hervorgerufen haben. Und dasselbe Atelier bringt uns diesmal eine genaue Copie eines Saales des Schlosses Esterháza bei Oedenburg. Auch aus einem andern Grunde ist das nicht auffallend. Denn neben der Werthschätzung des Alten spricht auch der Umstand mit, daß das genaue Copieren unverhältnißmäßig schwerer ist, als das beiläufige. Das weiß jeder Maler. Und da die Mittelmäßigkeit stets die Majorität ist, so werden sich bedeutend mehr Stimmen für dieses beiläufige Copieren aussprechen, als für das Correcte. Aber das Publicum kann sich ja entscheiden. ${ }^{\text {"67 }}$

Es ist lehrreich, mithilfe der beiden überlieferten Archivfotografien vom Saal zu untersuchen, wie sich die Kopie zum Original, d. h. dem Festsaal des soeben restaurierten Schloss in Fertőd, verhielt. Der Sitzungssaal des österreichischen Museums befand sich im ersten Stock gegenüber der Festtreppe, in der Mitte der Ringstraßenfront und verfügte über drei Fenster. Der Saal hatte jeweils eine Tür hinaus in den Arkadenflur und in die Nachbarräume. Somit wurde eine der Langseiten durch drei Fenster, die andere durch eine großformatige Tür und die beiden kürzeren Seiten durch jeweils eine kleinere Tür gegliedert. Im Gegensatz dazu waren im viel größeren Festsaal von Eszterháza jeweils zwei Türen an den Langseiten und an den kurzen Seiten drei Glastüren (in den Musiksaal) sowie drei Fenster zu sehen. Darüber hinaus kann der Umstand, dass der Festsaal des Schlosses zwei Stockwerke hoch war, während der Sitzungssaal im Wiener Museum nur über die Höhe der Festetage verfügte, als wesentlicher Unterschied in den Maßstäben eingeschätzt werden. Neben den vornherein gegebenen Abweichungen in der Wanddekoration bewirkte all dies hinsichtlich des Gesamtcharakters schwerwiegende Differenzen. Der wichtigste Unterschied war jedoch, dass während der ursprüngliche Apollosaal den Eindruck eines 
geräumigen, leichten Raumes erweckte, die im Museum eingerichtete Replik viel gedrungener erschien. Im Falle des Originals schienen die Statuen, die die vier Jahreszeiten symbolisierten, sowie die beiden Kamine und die Konsolentische im großen Raum sich gleichsam zu verlieren. Im Saal der Winterausstellung jedoch ergaben die viel gewichtiger als die ursprünglichen Konsolentische wirkende, mit schweren Bronzebeschlägen verzierte französische Kommode und der Münzschrank bzw. die in einer Unzahl aufgestellten großformatigen fernöstlichen Vasen mit ihren Cloisonnéverzierungen, der Sekretär an der kurzen Seite, die Armstühle, der Stuhl, die große Uhrenstatue, die mit drei Puttofiguren dekoriert und auf einem Marmorsockel aufgestellt war, und schließlich der Denizot'sche Frauenschreibtisch eine Wirkung, die das Gesamtbild des Museumssaales eher dem Stil und der Atmosphäre von zeitgenössischen Salons näherte. Dies wird noch deutlicher, wenn man bedenkt, dass während der Ausstellung in diesem Raum viel mehr Möbelstücke aufgestellt waren als auf den Fotografien sichtbar. Die Firma Schmidt schuf somit, nach dem Vorbild ihrer Wiener Galerie in der Singerstraße, eine Außenstelle für sich. ${ }^{68}$

Um zu der Problematik der genauen Kopien zurückzukehren: Eine Untersuchung der Details lehrt, dass lediglich die Stuckdekoration an der Decke und der Kamin eine genaue Nachahmung dieser Teile des Schlossraumes darstellten, und weder die Türen noch die Boiserie oder die Spiegel den Verzierungen des Saales in Eszterháza folgten. Nur zwei Möbelstücke, d. h. die beiden Eckschränke (die Kopien von zwei ursprünglich Boudin'schen Eckschränkchen in Eszterháza) sowie der Denizot'sche Frauenschreibtisch bezogen sich auf das Schloss Esterházy, während das restliche Mobiliar eine vom Eszterháza vollkommen unabhängige Nachahmung von namhaften französischen Rokokoprachtstücken darstellte. Links vom Eingang wurde jener mit einem Widderkopf verzierte und mit vergoldeten Bronzebeschlägen reichlich dekorierte Münzschrank als Kopie aufgestellt, der von den Brüdern Slodtz für das Versailler Privatgemach von Ludwig XV. entworfen und von dem Ebenist Gaudreaux verfertigt worden war. Dem schräg gegenüber stand die Kopie einer von Charles Cressent entworfenen Kommode aus der Sammlung Wallace. In der Ausstellung im Sitzungssaal des Museums wurden also die Zeit der Herrschaft Maria Theresias und ihre Einrichtungskultur durch diese genauen Kopien der Spitzenleistungen aus der Möbelkunst des französischen Rokoko - von Denizot, Cressent und Slodtz - sowie durch einen von François-Guillaume Ménageot entworfenen Gobelin repräsentiert.

Der Esterházy-Saal galt nicht nur als Sensation der Sonderausstellung; er wurde als Inneneinrichtung des Sitzungssaales dauerhaft beibehalten, da das Museum die eingebauten Elemente unentgeltlich von der Firma Schmidt erhielt. ${ }^{69}$ Zur Erinnerung: Der Direktor des Budapester Museums für Angewandte Kunst, Jenő Radisics, wollte nach der Millenniumsausstellung die Gelegenheit nicht ergreifen, die Elemente der Zimmerreihe der Esterházys in das fast leere Museumsgebäude zu integrieren. Nicht so Scala. Und mehr noch: Die ausgestellten Möbelstücke der Firma Schmidt durften im Saal bleiben. ${ }^{70}$ Der Liste, die die Firma Schmidt von den in der Ausstellung gezeigten Gegenständen erstellte, lässt sich entnehmen, dass die Raumausstattung reicher, gedrungener war als die, die auf der Fotografie in der Zeitschrift Kunst und Kunsthandwerk bzw. auf jener Aufnahme zu sehen war, die nicht in der Zeitschrift publiziert, sondern nur im Museumsarchiv aufbewahrt wurde. ${ }^{71}$ Das Verzeichnis legt die Schlussfolgerung nahe, dass der Ferstel'sche Türrahmen an der Seite des Arkadenflurs hinter einem grünen Portière, d. h. einer tapezierten Türdekoration auf einer Messingstange, verdeckt wurde. ${ }^{72}$ Auf den Fotografien ist es zwar nicht sichtbar, aber anhand der Liste lässt sich darauf schließen, dass an der flurseitigen Langseite Kopien von vier antiken Marmorbüsten auf vier roten Säulen aus Breccia-Marmor platziert wurden (mit den Darstellungen von Cicero, Domitian, Agrippina und Caracalla). Neben dem Barockstuhl mit pfauenfederverzierter Rückenlehne (Abb. 11) und drei Armstühlen mit Gobelinbezug, die jeweils auf den Fotografien abgebildet sind, kamen noch zwei Lehnstühle und zwei Sessel im Rokokostil, ein mit Bronzebeschlägen dekorierter Tisch im Louis-XVI.-Stil sowie ein „geschnitzter reicher Eichenholz[tisch]" im Louis-XV.-Stil ins Interieur. Diese Daten weisen darauf hin, dass im Gegensatz zu der Aufstellung auf den fotografischen Abbildungen auch die Mitte des Saales eingerichtet wurde. 


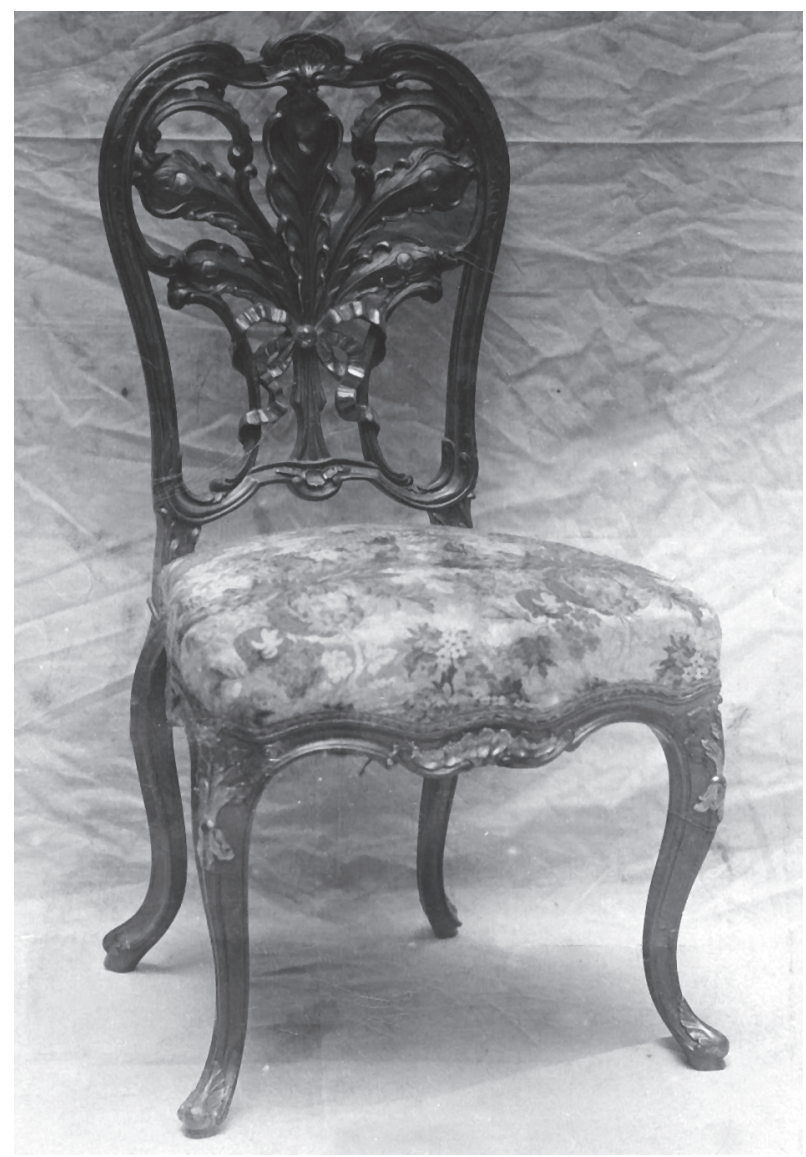

Abb. 11. Barocker Salonsessel aus dem Esterházy-Raum der Firma Friedrich Otto Schmidt 1898 in der Winterausstellung des k. k. Österreichischen Museums

(Museum Kiscell, Schmidt-Archiv, Fotoalbum „Kanapés und Sessel“", Inv.-Nr. Sch. 97.30.1)

Max Schmidt, dem der Erfolg des EsterházySaales Anlass genug gab und der die Erlaubnis von Scala nutzen wollte, beabsichtigte, im Sitzungssaal des Museums einen alle drei Monate zu erneuernden Schauraum als Außenstelle einzurichten. In einem an Scala gerichteten Brief vom 4. Februar 1899 brachte er folgende Idee vor: „Um nicht den Eindruck der Monotonie zu erregen, bin ich bereit, diese Objecte von 3 zu 3 Monate theilweise zu ersetzen, damit das Publicum nicht dazu Berichtigung findet zu sagen, das haben wir schon gesehen"."73 Gleichzeitig schlug Schmidt vor, den Saal für die kommende Winterausstellung so einzurichten, als wäre er ein bewohntes Interieur. Aus den Ausführungen zu dieser Idee wird zugleich deutlich, dass 1898 der Esterházy-Saal eigentlich als ein Schaustück für die Befriedigung des Geschmacks und der Einrichtungsansprüche der Aristokratie ausgestattet wurde: , Um auch in der nächsten Winterausstellung diesen Raum wieder in anderer Form wirken zu lassen, mache ich Euer Hochwohlgeboren den Vorschlag, den Saal so zu decorieren, wie beispielsweise der Fürst Esterházy oder irgend ein reicher Magnat heutzutage einen derartigen Saal bewohnt. Nach der Aussage mehrerer Aristokraten hatte der Saal nemlich den Fehler, weniger wie ein Wohnraum zu wirken, als vielmehr wie ein Musealzimmer, welches unbewohnbar ist. Ich glaube, daß diese Änderung Interesse erwecken würde. ${ }^{674}$

Die Idee Schmidts, für die man zwar nie öffentlich warb, konnte realisiert werden: In der Winterausstellung von 1899 waren Kopien von äußerst kostbaren französischen Rokokomöbeln zu sehen und auch die Ausstellung von 1901 wurde für die Präsentation von Möbelstücken genutzt. In diesem Fall jedoch musste die Firma Schmidt den Saal mit drei anderen Firmen teilen. ${ }^{75} \mathrm{Im}$ Esterházy-Saal wurden noch in den 1910er Jahren Schmidt-Ausstellungen veranstaltet. Die Schmidt'sche Ausstattung des Sitzungssaals wurde bis in die 1920er Jahre beibehalten und fungierte als Referenzarbeit bzw. Schauraum der Firma. ${ }^{76}$

\section{DER ESTERHÁZY-SAAL IM KRAFTFELD DES WIENER KUNSTGEWERBEVEREINS UND DER SECESSION}

Der seit dem Sommer 1897 als Direktor tätige Arthur von Scala führte radikale Reformen im institutionellen Betrieb des Museums durch. Bereits die erste, groß angelegte Winterausstellung galt als Kampfansage an den Kunstgewerbeverein, der die Ausrichtung des Museums bis dahin maßgeblich prägte. Im Gegensatz zu den Weihnachtsausstellungen der früheren Jahre beauftragte Scala mit der Einrichtung der Schau und mit der Materialauswahl nicht mehr den Verein, der seinen Sitz im Museum selbst hatte. Stattdessen organisierte Scala eine Präsentation der englischen Inneneinrichtungsmode und initiierte somit einen radikalen Wechsel in der Ausstattungskultur. ${ }^{77}$ Während der Ausstellung und im darauf folgenden Frühling entfaltete sich eine 


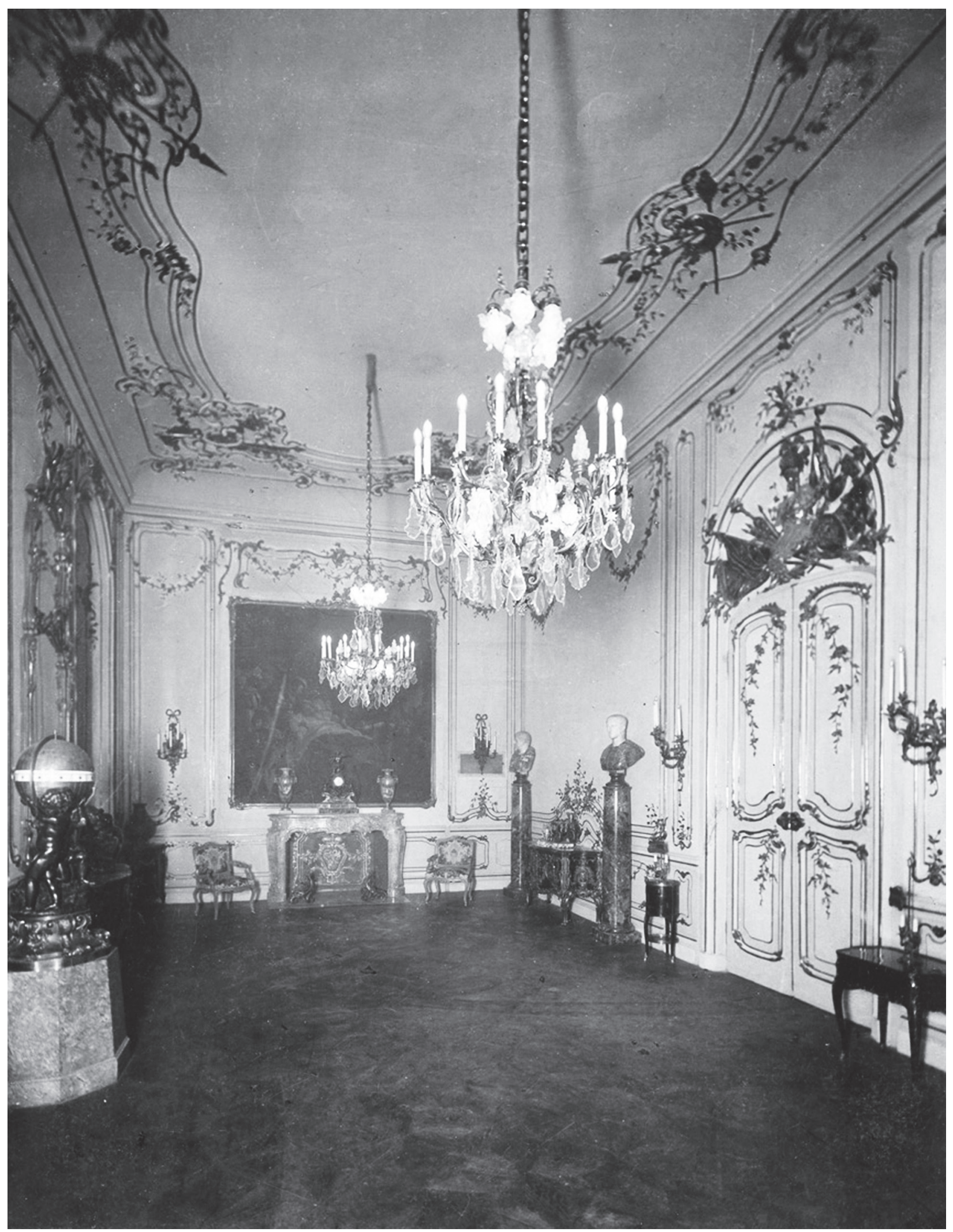

Abb. 12. Esterházy-Raum der Firma Friedrich Otto Schmidt 1898 in der Winterausstellung des k. k. Österreichischen Museums (MAK, Mappe T2-B16-L15.35/C, I.N. 7326/2 


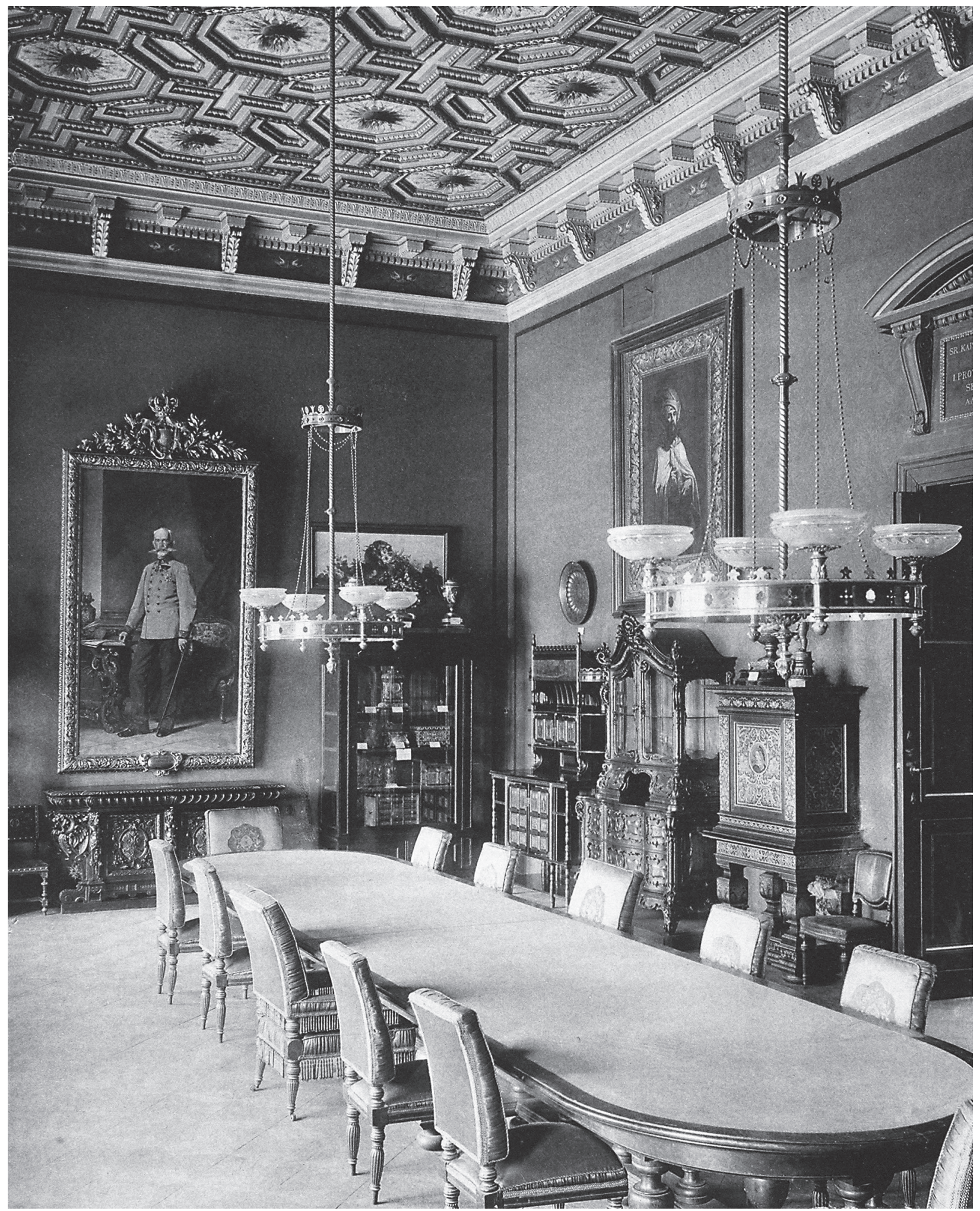

Abb. 13. Der Sitzungssaal vor seinem Umbau zum Esterházy-Prachtsaal (MAK, I.N. BI-14735-2 
ungewöhnlich heftige, ja impulsive Polemik zwischen dem um die eigenen Privilegien und den eigenen Geschmack besorgten Verein und dem neuen Direktor bzw. den ihn unterstützenden Firmen. Hinsichtlich des Ausstattungsstils, wie er innerhalb des Kunstgewerbevereins gepflegt wurde, bedeutete das Programm von Arthur von Scala einen radikalen Wandel an zwei wesentlichen Punkten: Einerseits förderte er die Übernahme der zeitgenössischen und historischen Möbelstile aus England, andererseits propagierte er im Widerstand gegen die gängige Praxis des eklektischen Kopierens, der Weiterentwicklung und Mischung von historischen Stilen jenes Prinzip, das am prägnantesten in den Schriften von Adolf Loos überliefert ist: „Copiren, aber streng copiren! ${ }^{678}$ Als programmatisches Interieur fürs Erstere galt der von Josef Urban und Heinrich Leffler entworfene englische Damensalon, der in der Winterausstellung von 1897 zu sehen war, und fürs Letztere der von der Firma Schmidt ausgestattete Esterházy-Saal.

In der Entscheidung Scalas, die Festsaalskopie aus dem Schloss Esterházy auch nach der Ausstellung von 1898 dauerhaft zu behalten, darf wohl jene praktische Erwägung eine Rolle gespielt haben, dass dem Museum unbedingt Kosten verursacht worden wären, hätte die Saaldekoration der Ausstellung abmontiert oder die alte wiederhergestellt oder aber eine ganz neue gestaltet werden sollen, da mit der Verfertigung des Esterházy-Interieurs die Kassettendecke von Heinrich Ferstel, die Supraporte der Eingangstür sowie die Verkleidung der Seitenwände entfernt worden waren. Ein wichtigerer Aspekt dürfte jedoch gewesen sein, den Sitzungssaal, der bis dahin als Ausstellungs- und Sitzungsraum des Kunstgewerbevereins fungierte, zum Ausdruck seines eigenen Programms zu machen und ihn nach seinem eigenen Geschmack zu gestalten. Gleichzeitig expedierte er den Kunstgewerbeverein endgültig aus dem Museumsgebäude hinaus (Abb. 12-13) und brachte für den Museumsbetrieb eine neue Epoche, indem er der erzherzoglichen Schirmherrschaft absagte ${ }^{79}$ und ein neues Museumsstatut verabschiedete bzw. das Kuratorium in neuer Zusammensetzung aufstellte. ${ }^{80}$

Scalas Reformen stießen jedoch bald auf den erbitterten Widerstand der Modernen. Im Winter 1899 nahm Otto Wagner die künstlerische Originalität und Freiheit in Schutz und ritt gerade gegen die im Esterházy-Saal verkörperte Kopierpraxis sowie die Bevormundung durch die $\mathrm{W}$ issenschaft von Gewerbe und Kunstgeschichte eine Attacke. ${ }^{81}$ Von nun an schienen das von der Praxis des Historismus abweichende Einrichtungsideal des Aristokratenkreises hinter Scala, die Welt der Möbel des englischen Adels und der genauen Stilkopien sowie die modernistische Ausrichtung der Secession nicht mehr vereinbar zu sein.

\section{ANMERKUNGEN}

\footnotetext{
${ }^{1}$ Schmidt Miksa nyilatkozata [Erklärung von Max Schmidt]. In: Az Est v. 5. Dezember 1934, p. 11.

${ }^{2}$ Cf. Szokolszky Bertalan: A százéves kassai püspökség 1804-1904 [Das hundertjährige Kassaer Bistum 1804-1904]. Kassa: Vitéz 1904, p. 140.

${ }^{3}$ Zsigmond Bubics ließ seine eigene Residenz in Kassa wie auch die von ihm erworbene Kehlburg in Südtirol mit der Firma Schmidt restaurieren. Cf. Rostás, Péter: Die ersten fünfzig Jahre des Einrichtungshauses Friedrich Otto Schmidt in Wien. In: Földi-Dózsa, Katalin-Hergovich, Marianne [Hg.] Zeit des Aufbruchs. Budapest und Wien zwischen Historismus und Avantgarde. Wien: Kunsthistorisches Museum 2003, pp. 327-340; Rostás Péter: Mágnások lakberendezője. A Friedrich Otto Schmidt lakberendezőház története 1858-1918 [Ein Innenarchitekt der Magnaten. Die Geschichte des Ausstattungshauses Friedrich Otto Schmidt]. Budapest: Geopen 2010, p. 35 und pp. 68-71.

${ }^{4}$ Museum von Kiscell, Schmidt-Archiv, Inv.-Nr. Sch. 97.15.1. Pénztárkönyv [Kassabuch] 1890-1892 bzw. Sch. 97.16.1. Pénztárkönyv [Kassabuch] 1892-1894

${ }^{5}$ Cf. 3. Oktober 1891: „Per Max Reise nach Kismarton \& Eszterház 26.25 fl.“; 28. Oktober 1891: „Per Wottke à Conto Esterház 25 fl.“; 31. Oktober 1891: „Per Reise nach Esterház
}

\& Pottendorf 29,75 fl. “; „Per Max Reise nach Esterház 28,75 fl."; „Per Wagner Esterház 50 fl."; 11. November 1891: „Per Kauba Saldo von Abreise Ester[háza] 5,30 fl." Die einzelnen Namen bezeichnen nicht unbedingt die vor Ort arbeitenden Handwerker. Ausgehend von der späteren Praxis der Firma Schmidt scheint es wahrscheinlicher, dass sich die Namen auf die Werkstattleiter beziehen und die einzelnen Posten jene Summen bezeichnen, die für die z. T. in der Wiener Werkstatt und z. T. vor Ort ausgeführten Arbeiten in Zusammenhang mit dem jeweiligen Auftrag angewendet wurden.

${ }^{6}$ Cf. 28. Dezember 1891: "Per Josef Wagner Saldo 31/12 91 Esterhaz 62.53 fl.": ..Per J. Kauba Saldo 31/12 91 Esterhaz 56,04 fl."; 2. Januar 1892: „Per Neumann Esterhaz 30 fl."; „Furch Esterhaz à Conto 20 fl."; 11. Januar 1892: „Reise nach Esterhaz 22,25 fl."

${ }^{7}$ Cf. 9. April 1892: „An fürstlich Esterhazy Haupt-Cassa Saldo $12258 \mathrm{fl}$."

${ }^{8}$ Cf. 11. Juli 1892: „An Fürst Nicolaus Esterhazy II. Rechnung für den linken Schloßtrakt, Saldo 15.810,75 fl."

In Bezug auf die auch diachronisch angeführten Angaben, die sich auf die Funktionen der Schlossräumlichkeiten beziehen, d. h. auf das historische Raumbuch cf. Dávid Ferenc: A fertődi Esterházy-kastély történeti helyiségkönyve: funkciók 
és falburkolatok [Das historische Raumbuch des EsterházySchlosses in Fertőd: Funktionen und Wandbekleidungen]. In: Ars Hungarica 30 (2002), pp. 237-320.

${ }^{10}$ Cf. 30. April 1892: „Per Josef/Johann Wagner Tischler (Esterhaz) 15 fl."“: 7. Juli 1892: ..Per Hässig Schlosser Esterhaz 119 fl."; 13. Juli 1892: .Otto Reise Esterhaz 21 fl." Der Name der Firma Friedrich Otto Schmidt wurde einerseits aus dem Namen des Gründers Carl Friedrich Heinrich Schmidt und andererseits aus dem Namen seines ältesten Sohns Otto Erdmann Schmidt kreiert.

${ }^{11}$ Den Abrechnungen des Kassabuchs zufolge erhielt Otto regelmäßig Unterstützung für seinen Lebensunterhalt in einer Höhe von 30-35 Forint monatlich. Er kam mehrmals nach Eszterháza und, wie die Angaben im Kassabuch in den dadurch belegten vier Jahren bezeugen, besuchte er keine anderen Orte. Dies deutet darauf hin, dass dem ältesten Bruder, der sonst in den Firmenaktivitäten kaum tätig war, im Zuge der Restaurierungsarbeiten in Eszterháza eine konkrete Aufgabe zukam.

12 Am 18. Januar und am 28. Februar 1893 erhielt die Firma Friedrich Otto Schmidt jeweils eine Auszahlung von 5000 Forint für Möbel. Am 23. August 1893 überwies der Fürst Miklós Esterházy den Schmidts 10861 Forint und 15 Fillér. Am 31. Oktober erfolgt der Ankauf von 2000 Blättern Gold und von blauem Moiré aus Seide für die Ausstattungsarbeiten des Schlosses. Am 8. Januar 1894 überweist Fürst Miklós den Schmidts 19028 Forint.

${ }^{13}$ A kiállitási igazgatóság jelentése az 1896-iki Ezredéves Országos Kiállítás előmunkálatairól az 1894-ik évben [Bericht der Ausstellungsdirektion über die Vorbereitungen zur Landesweiten Millenniumsausstellung 1896 im Jahr 1894]. Budapest [s. n.] 1895, p. 56.

${ }^{14}$ Ibid.. p. 62. Im Archiv des Museums für Angewandte Kunst ist eine Fotografieserie mit dem Siegel des Kreises der Kunstfreunde zu finden, aus der 1894 Gyula Pasteiner fünf Interieuraufnahmen publizierte. Cf. Pasteiner Gvula: Esterháza kastély [Das Schloss von Esterháza]. In: Müvészi Ipar 9 (1894), pp. 147-174, hier p. 159, 161, 163, 165, 167. Ich glaube, diese Serie kann mit jenen Fotografien als identitsch angesehen werden, die die Kommission verfertigen ließ. Es ist nämlich anzunehmen, dass das Material durch János Szendrei, einen Mitglied der Vorbereitungskommission, nach Ausstellungsabschluss in den Besitz des Kreises der Kunstfreude gelangte, da Szendrei als Sekretär des Kreises tätig war. Es ist also eher unwahrscheinlich, dass die Fotografien ursprünglich für die vom Kreis der Kunstfreunde herausgegebene Reihe Magyar Mükincsek [Ungarische Kunstschätze] gemacht worden wären. Darauf deutet auch hin, dass keine der Fotografien in diesem Band reproduziert wurde. Cf. Dávid Ferenc: Eszterháza belső terei [Die Innenräume von Eszterháza]. In: Ars Hungarica 28 (2000), pp. 73-95.

${ }^{15}$ A történelmi föcsoport végrehajtó bizottságának ülése [Die Sitzung des Exekutivkomitees der historischen Hauptgruppe]. In: Millennium v. 1. Juli 1894, pp. 2-4. Dem Bericht des Sachbearbeiters im Komitee der Hauptgruppe, Béla Czobor, zufolge kamen nach dem Aufruf vom 27. März 1894 mehr Rückmeldungen von Prälaten als von Aristokraten ein. „Unter den Aristokraten meldete jedoch Graf János Pálffy, auf dessen Sammlung die Direktion einen besonderen Wert legt. schriftlich seine Teilnahmebereitschaft an der historischen Ausstellung wie auch Pál Esterházy, der dies durch den Bischof Zsigmond Bubics mündlich ausrichten ließ, wobei [Esterházy] seine Interieurs aus der Zeit von Ludwig XIV-XV. zu Ausstellungszwecken anbot."

${ }^{16}$ Dávid 2002, p. 46. Kassa, érseki levéltár, Bubics Zsigmond levelei [Erzbischöfliches Archiv von Kassa, Briefe von Zsigmond Bubics]. 2. fasc.. Handschriftlicher Brief von Max Schmidt an Zsigmond Bubics vom 24. August 1896, Budapest, auf einem Briefpapier mit der Kopfzeile „Friedrich Otto Schmidt".

${ }^{17}$ Cf. ibid.: .,Darf ich an die Restaurierung der Bildergallerien erinnern?"

${ }^{18} \mathrm{Im}$ Sommer 1897 war nämlich erst die Ausgleichung der nicht bezahlten Rechnungen auf der Tagesordnung. In einem Brief vom 16. Juli 1897 versprach Zsigmond Bubics, die Ab- rechnungen bis zum Januar 1898 abzuschließen: „Geehrter Herr Schmidt, [...] Ich will Thnen kurz das Resultat meiner Reise mittheilen. Im December, dann Jänner 98 wird alles liquidirt, trachten Sie auf einem Blatt die Localitäten \& Arbeiten übersichtlich auf einem Blatt dem Director zur Einsicht vorzulegen, damit er einsehe, welch enorme Arbeiten Sie vollendet haben. Der Director ist auf 14 Tage, 3 Wochen nach Marienbad [...]". (Schmidt-Archiv, Wien). Die Auszahlungen verzögerten sich jedoch weiterhin und der Direktor der Zwangsverwaltungszentrale erließ am 25. Januar 1899 einen Schuldbrief für Schmidt. In einem Brief vom 25. Januar 1899 teilt Zsigmond Bubics Max Schmidt Folgendes mit: „.Auch übersende ich da Belastungsdocument, welches Hr. Haller unterzeichnete und Thr eigen ist" (Schmidt-Archiv, Wien).

${ }^{19}$ Vadászi Erzsébet: Magyar Versália [Ungarische Versalie]. Budapest: Műemlékek All. Gondnoksága 2007, Kat.-Nr. $49-51$.

${ }^{20}$ Ibid., Kat.-Nr. 52.

21 Nádasdy Ferenc Múzeum, Sárvár, Inv.-Nr. 87.130.1.

${ }^{22}$ Vadászi 2007, p. 32 (Abb. 26) sowie p. 208 (Kat.-Nr. 55) und p. 215 (Kat.-Nr. 21).

${ }^{23}$ Die Eintragung im Inventarbuch besagt bloß, dass es sich um .Denizot" handelt. Die biografischen Daten wie auch der Stil des Möbelstücks lassen darauf schließen, dass es sich um Pierre Denizot handelt, der für den Comte D'Artois, den Schwager von Marie Antoinette, arbeitete. Es ist nicht mehr festzustellen, auf welcher Information genau die Eintragung im Inventarbuch basiert, aber es muss sich wohl um eine Bezeichnung am Möbelstück gehandelt haben. Das Tischchen wurde um 1894 in Eszterháza fotografiert. Cf. Vadászi 2007. p. 213 (Kat.-Nr. 16).

${ }^{24}$ Winterausstellung. K. $k$. österr. Museum für Kunst und Industrie. [Wien] [s. n.] [1898], Kat.-Nr. 542 und 542a. Der Tisch war auch in der W interausstellung 1900 präsentiert und zwar im von Schmidt ausgestellten Frauengemach im Rokokostil. Cf. Winterausstellung 1900-1901, k. k. Österr. Museum f. Kunst und Industrie. [Wien] [s. n.] [1900], p. 17.

${ }^{25}$ Cf. General Waren Lager Buch (Schmidt-Archiv, Wien) $252,4473-77,6936$

${ }^{26}$ IM. Adattár [Museum für Angewandte Kunst, Archiv], KLT 3334/1,10, 20. Die erwähnten drei Möbelstücke (ein Schreibtisch, ein Salontischchen und eine Kommode) wurden im Salon Nr. 15 im ersten Stock des Schlosses in Királyfa inventarisiert. Cf. Horváth Hilda: Gróf Pálffy János mügyüjteménye [Die Kunstsammlung des Grafen János Pálffy]. Budapest: Akadémiai 2007, p. 69.

${ }^{27}$ Da uns bloß eine Fotografie vom erwähnten Tisch als Quelle zur Verfügung steht, lohnt es sich, die Beschreibung von Radisics ausführlich zu zitieren, denn ihr sind solche Details zu entnehmen, die auf der fotografischen Aufnahme nicht sichtbar werden: „Schreibtisch. Palisander mit Einlagen aus Buchsbaum, Ahorn, Rosenbaum und anderen gefärbten Holzarten. Er steht auf vier gebogenen Füßen, deren Kanten die ganze Länge hindurch mit einer Girlande aus ziselierten und aus Bronze gegossenen Riedblättern verziert sind, mi jeweils einer durchbrochenen Kartusche am Abschluss. An den Seitenkanten sind ebenfalls Bronzeverzierungen zu sehen. Der Vorderteil der Platte mit Bronzekante kann mithilfe eines Scharniers hinuntergeklappt werden. Innen werden die entsprechend geformten Behälter durch Platten verdeckt, die rechts und links seitlich aufgehen. Zwischen diesen befindet sich ein Schachtelchen. das auf Federdruck hinausspringt und das an der schmalen Seite jeweils eine bzw. unter ihm noch eine Geheimlade beinhaltet. Die andere, größere Hälfte der Tischplatte erhebt sich ebenfalls mithilfe einer Feder. Die Verzierungen widerspiegeln Rokokogeschmack: Blumen, Musikinstrumente und andere unterschiedliche Instrumente sind von teilweise architektonisch gestalteten Motiven umgeben. Höhe: $0,72 \mathrm{~m}$. Länge: $0,70 \mathrm{~m}$. Breite: $0,485 \mathrm{~m}$. Es ist eine nach dem Geschmack der Zeit Ludwigs XV. angefertigte, moderne Kopie, deren Original sich im Schloss von Eszterháza befindet Verfertigt von Otto Friedrich Schmidt [sic!] in B [uda]pest. Schätzwert: 800 K." 
${ }^{28}$ Kassa, érseki levéltár, Bubics Zsigmond levelei [Erzbischöfliches Archiv von Kassa, Briefe von Zsigmond Bubics], 2. fasc., Levél Max Schmidt keze írásával Bubics Zsigmondnak 1896. augusztus 24-én Budapestről [Handschriftlicher Brief von Max Schmidt an Zsigmond Bubics vom 21. September 1896, Budapest]; auf einem Briefpapier mit der Kopfzeile ..Friedrich Otto Schmidt".

${ }^{29}$ Brief von Alois von Liechtenstein an den Regenten Johann II. von und zu Liechtenstein vom 12. Dezember 1903, Wien (Wien, Hausarchiv Liechtenstein, 9482/1903).

${ }^{30}$ Der erste Befund zum Auftrag in Eszterháza als Grund für die Niederlassung in Ungarn ist ein Inserat in Form von einer Selbstdarstellung der Firma: A Schmidt-féle mụbútorgyár [Die Schmidt'sche Kunstmöbelfabrik]. In: Szalon Újság v. 31. Oktober 1902, pp. 13-14.

${ }^{31}$ Herceg Esterházy Család Fraknói Gazdasági Levéltára, Központi Jószágkormány Wirtschaftsarchiv der fürstlichen Familie Esterházy in Fraknó, Zentrale Domänenverwaltung], 2327/1898. Der Brief wurde von Gábor Alföldy im EsterházyArchiv in Fraknó ausfindig gemacht. An dieser Stelle möchte ich ihm herzlichst danken, ihn mir zur Verfügung gestellt zu haben.

${ }^{32}$ Die Firma scheint diesem Grundprinzip tatsächlich gefolgt zu sein. In den 1930er Jahren berichtete Baron Ferenc Hatvany, einer der größten Auftraggeber der Firma, dass er, als er Max Schmidt in einer Ausstellung begegnete, gewisse Einwände hinsichtlich der gelieferten Möbelstücke hervorbrachte, worauf Max Schmidt sich bereit erklärte, die gesamte Innenausstattung zurückzukaufen.

${ }_{33}^{3}$ Cf. Anm. 31.

${ }^{34}$ Cf. Budapesti Hírlap v. 29. September 1893, p. 4.

${ }^{35}$ Fittler Kamill: A történelmi kiállítás [Die historische Ausstellung]. In: Pesti Napló v. 12. Juni 1896, pp. 5-6.

${ }^{36}$ Für die Beschreibung der Zimmer cf. A történelmi fö́csoport hivatalos katalógusa [Offizieller Katalog der historischen Hauptgruppe]. Budapest: Kosmos 1896, pp. 362-363; Gelléri Mór (Hg.): Az Ezredéves Országos Kiállitás Kalauza [Führer durch die Landesweite Millenniumsausstellung]. Budapest: Kosmos 1896, p. 168; Bálint Zoltán: Az Ezredéves Kiállitás Architekturája [Die Architektur der Millenniumsausstellung]. Budapest [s. n.] 1897, p. 36; Szalay Imre: A reneszánsz épületcsoport [Die Baugruppe im Renaissancestil]. In: ders. (Hg.): Magyarország Mükincsei II. Budapest: Magyar Könyvkereskedő Részvénytársaság 1902-1903, pp. 285-290, hier p. 288; Radisics Jenő: A magyar művészi ipar az Ezredéves Kiállításon [Das ungarische Kunstgewerbe in der Millenniumsausstellung]. In: Szalay Imre (Hg.): Magyarország. történeti emlékei az 1896. évi Ezredéves Országos Kiállitáson. Budapest: Gerlach [1897-1903], Bd. II, pp. 402-417, hier pp. 416-417; Czobor Béla: A Történelmi Kiállítás [Die Historische Ausstellung]. In: Matlekovits Sándor (Hg.): Magyarország közgazdasági és közmüvelödési állapota ezeréves fennállásakor és az 1896. évi Ezredéves Kiállítás eredménye. Bd. V: Az 1896. évi Ezredéves Kiállitás eredménye. Történelmi kiállítás. Népra$j z$. Budapest: Pesti Könyvnyomda 1898, pp. 1-64, hier pp. 50-52; Fittler Kamill: Lakberendezés [Inneneinrichtung]. In: Matlekovits (Hg.) 1898, pp. 299-317, hier pp. 312-313.

${ }^{37}$ Der offizielle Katalog spricht irrtümlich von Trumeaux im Louis-XVI.-Stil; cf. A történelmi fócsoport hivatalos katalógusa 1896, p. 362.

${ }^{38}$ Unter den zeitgenössischen Autoren, die eine Beschreibung der Saalreihe baten, war Zoltán Bálint der einzige, der in Bezug auf dieses Zimmer ein konkretes Vorbild aus Eszterháza erwähnte: Es sei „eine etwaige Nachahmung des fürstlichen Salons im Erdgeschoss des Flügels in Richtung Eszterháza“" (Bálint 1897, p. 36). Dies ist aber mit Sicherheit eine irrtümliche Behauptung, da die auffallendsten Merkmale der Säle im Fürstenappartement die in der Boiserie angebrachten kleinen Ölbilder waren. Bálint muss hier diesen Saal mit dem in der Ausstellung präsentierten Vieux-Laque-Zimmer verwechselt haben, als dessen Vorbild in der Tat das sog. indische Kabinett im Erdgeschoss des Fürstenappartements fungierte.

${ }^{39} \mathrm{Da}$ von diesem Raum keine Fotografie überliefert ist, kann sein Bild nur aus Beschreibungen rekonstruiert werden.
Zoltán Bálint meinte etwas abschätzig, das Zimmer sei „mit seinen Vie[u]x-Laque-Abbildungen ein schwaches Nachbild des Vie[u]x-Laque-Salons im Schloss, der im Übergangsstil von Ludwig XV. und XVI. ausgestattet wurde" (Bálint 1897, p. 36). Der Beschreibung von Radisics zufolge soll die Kopie originaltreu gewesen sein: „Die Wände zeigten die auch heute vorhandenen, originalen chinesischen Lackeinlagen des Schlosses von Eszterháza in treuer Abbildung" (Radisics [1897-1903], p. 417). Fittlers Beschreibung enthält auch eine Auflistung der Inneneinrichtung: „Das Mobiliar besteht aus einem Vieux-Laque-Schrank, einem Kristallkronleuchter, einem Sofa und aus Stühlen, die einen Goldbrokatbezug haben." Fittler Kamill: Lakberendezés [Inneneinrichtung]. In: In: Matlekovits (Hg.) 1898, pp. 299-317, hier p. 313.

${ }^{40}$ Cf. Fittler Kamill: Építészet [Architektur]. In: Matlekovits (Hg.) 1898, p. 80.

${ }^{41}$ Telesko. Werner (Hg.): Die Wiener Hofburg 1835-1918. Der Ausbau der Residenz vom Vormärz bis zum Ende des "Kaiserforums". Wien: Verlag der Österreichischen Akademie der Wissenschaften 2012, pp. 242-255.

${ }^{42}$ Fittler: Lakberendezés 1898, p. 313.

${ }^{43}$ Radisics 1897, p. 416.

${ }^{44}$ Ibid., p. 417.

${ }^{45}$ Herceg Esterházy Család Fraknói Gazdasági Levéltára, Központi Jószágkormány [Wirtschaftsarchiv der fürstlichen Familie Esterházy in Fraknó, Zentrale Domänenverwaltung], 3744/1896. Die Akten zur Zimmerreihe in der Millenniumsausstellung wurden von Gábor Alföldy erforscht. Für die Erlaubnis, auch diese Dokumente zu benutzen, bedanke ich mich bei ihm.

${ }^{46}$ Kassa, érseki levéltár, Bubics Zsigmond levelei [Erzbischöfliches Archiv von Kassa, Briefe von Zsigmond Bubics], 2. fasc.

${ }^{47}$ Herceg Esterházy Család Fraknói Gazdasági Levéltára, Központi Jószágkormány [Wirtschaftsarchiv der fürstlichen Familie Esterházy in Fraknó, Zentrale Domänenverwaltung], 3744/1896 und IM Adattár [Museum für Angewandte Kunst, Archiv], 29/1897.

${ }^{48}$ IM Adattár [Museum für Angewandte Kunst, Archiv], $29 / 1897$

${ }^{49}$ Ibid. Als Standort für das Museum, das vom Landwirtschaftsminister Ignác Daránvi initiiert wurde, war zunächst der Pavillon der Millenniumsausstellung vorgesehen. Da der Zustand des Gebäudes jedoch wegen der Feuchtigkeit von unten schnell baufällig wurde, entschied man sich 1898-1899, das gesamte Ensemble aus festem Material wieder aufzubauen.

${ }^{50}$ IM Adattár [Museum für Angewandte Kunst, Archiv], 85/1897.

${ }^{51}$ IM Adattár [Museum für Angewandte Kunst, Archiv], $292 / 1897$

52 Elözetes tájékoztató a Gazdasági Múzeumban [Zwischenbescheid im Wirtschaftsmuseum]. Budapest: Gazdasági Múzeum 1897, p. 15.

${ }^{53}$ Am 19. September 1899 benachrichtigte das Museum für Landwirtschaft das Museum für Angewandte Kunst, dass das Gebäude bald abgerissen werde und daher die beanspruchten Gegenstände aus den Zimmern abzutransportieren wären (Mezőgazdasági Múzeum, Adattár [Museum für Landwirtschaft, Archiv], 807/1899)

54 „Die sog. Schmidt'schen Wandverkleidungskopien wurden ohne Inventur bis November 1976 in Budapest aufbewahrt, anschließend wurden sie durch Gutschrift ins Schloss von Fertőd gebracht (IM, Adattár [Museum für Angewandte Kunst, Archiv], 926-9/76)." Cf. Vadászi 2007, p. 183.

55 Cf. Winterausstellung [1898], Kat.-Nr. 37-39, 48, 182, 231-232, 442-444.

${ }^{56}$ In den provisorischen Bauten der Millenniumsausstellung waren die Wandverkleidungen, die Stuckverzierungen und Böden von vornherein für provisorischen Gebrauch vorgesehen; der Bau eines höheren Raums im Renaissanceflügel und seine Einrichtung nach dem Vorbild des Saals in Eszterháza wäre eine offensichtlich unverhältnismäßige Investition gewesen. 
Für die Kosten des im österreichischen Museum eingerichteten Raumes kam, wie ich zeigen werde, das Museum selbst auf, da der neu ausgestattete Sitzungssaal für eine dauerhafte Verwendung geplant war.

${ }^{57}$ Cf. Haiko, Peter: Kosmopolitische Neorenaissance versus österreichischer Neobarock. In: Wenzel, Cornelia-Laudel, Heidrun (Hg.): Stilstreit und Einheitskunstwerk. Internationales Historismus-Symposium, Bad Muskau, Juni 1997. Dresden: Gwz Graphische Werkstätten Zittau 1998, pp. 199-208 und Nierhaus, Andreas: Höfisch und österreichisch. Zur Architektur des Neobarock in Wien. In: Csáky, Moritz-Celestini, Federico-Tragatschnig, Ulrich (Hg.): Barock - ein Ort des Gedächtnisses. Interpretament der Moderne/Postmoderne. Wien et al.: Böhlau 2007, pp. 79-99.

${ }^{58}$ Ludwig Hevesi fasste die Geschehnisse im Jahr 1899 wie folgt zusammen: „Die Ausstellung fiel österreichischer aus, als irgend eine in der früheren Periode [...]." Ludwig Hevesi: Die Winterausstellung im Österreichischen Museum. In: Kunst und Kunsthandwerk 1 (1900), pp. 1-33, hier p. 1.

${ }^{59}$ Cf. MAK, Archiv, 276/1899.

${ }^{60}$ H. [Ludwig Hevesi]: Die Winterausstellung im Oesterreichischen Museum. In: Fremden-Blatt v. 13. November 1898 , p. 6. und Folnesics, Jos[ef]: Winterausstellung im Oesterreichischen Museum. In: Neues Wiener Tagblatt v. 15. November 1898, pp. 1-3, hier p. 2.

${ }^{61}$ Minkus, Fritz: Die Winterausstellung im k. k. Museum für Kunst und Industrie in Wien. In: Kunstgewerbeblatt, 10 (1899), pp. 103-110, hier p. 106.

${ }^{62}$ Ibid., p. 109.

${ }^{63}$ Ibid.

${ }^{64}$ Cf. Egger, Hanna: Die Anfänge des k. k. Österreichischen Museums für Kunst und Industrie und der Wiener Schule der Kunstgeschichte. In: Noever, Peter (Hg.): Kunst und Industrie. Die Anfänge des Museums für angewandte Kunst in Wien. Wien: Hatje Cantz 2000, pp. 279-283; Wickhoff, Franz: Die Zukunft der Kunstgewerbemuseen. In: Kunst und Kunsthandwerk 1 (1898), pp. 15-20

${ }^{65}$ Schiller, Friedrich: Maria Stuart. Ein Trauerspiel. Tübingen: Cotta 1801, p. 20.

${ }_{66}$ Minkus 1899, p. 109.

${ }^{67}$ Loos, Adolf: Wanderungen im Oesterreichischen Museum. In: Neue Freie Presse v. 27. November 1898, p. 9, auch in: ders.: Ins Leere gesprochen. Gesammelte Schriften 18971900. Hg. v. Adolf Opel. Wien: Prachner 1997, pp. 178-179; cit. in: Ottillinger, Eva B.: Adolf Loos. Wohnkonzepte und Möbelentwürfe. Wien-Salzburg: Residenz 1994, p. 75.

${ }^{68} \mathrm{Zu}$ den Schauräumen der Firma Schmidt, die im Barockpalais Neupauer-Breunner eingerichtet wurden, cf. Rostás 2010, p. 146 und pp. 151-152.
${ }^{69}$ Cf. MAK, Archiv 1337/1899, Brief von Max Schmidt v. 23. November 1899. Die Wandleuchten, die Kronleuchter und die Feuerböcke gehörten nicht zur geschenkten immobilen Ausstattung, aber einen Teil davon bildeten der aus grauem Engelsberger Marmor verfertigte Kamin auf einer Grundplatte mit Marmorinkrustation sowie zwei Türen, die mit vergoldeten Schnitzereien verziert waren und aus dem in den frühen 1890er Jahren abgerissenen Palais Schwarzenberg stammten.

${ }^{70}$ In einem Brief vom 4. Februar 1899 bedankte sich Max Schmidt bei Scala, dass dieser erlaubte, den Esterházy-Saal aufrechtzuerhalten und die Möbelstücke weiterhin im Saal wie in einer Ausstellung zu belassen (cf. MAK. Archiv, 132/1899).

${ }^{71}$ Cf. Kunst und Kunsthandwerk 2 (1899) und MAK, Vorbildersammlung, Mappe T2-B16-L15-35/C, I. N. 7326/1-2.

72 ,1 Grün Jaspe Portère mit Messingstange, 2 Broncirte Eisenständer \& geknüpfte Zierschnüre, 2 Eisenkloben \& Ringen“" (MAK, Archiv, 132/1899).

${ }^{73}$ MAK, Archiv, 132/1899.

${ }^{74}$ Ibid.

75 Zur Raumnutzung finden sich im offiziellen Katalog von 1901 keine Hinweise, sie kann jedoch aus dem Briefwechsel zwischen dem Museum und der Firma Schmidt, in dem es sich um Probleme der Abrechnungen bezüglich der elektrischen Beleuchtung handelt, rekonstruiert werden (MAK, Archiv, $331 / 1902)$.

${ }^{76} \mathrm{Im}$ Februar 1911 stellte die Firma eine Liste der zu dieser Zeit im Esterházy-Saal befindlichen Gegenstände zusammen und schickte dem Museum eine Rechnung über den Filzteppich und die Spiegel. Das Museum kaufte im Jahr 1919 nach mehrfachen Ansuchen und juristischen Aufforderungsschreiben den roten Fußbodenfilzteppich schließlich an (MAK, Archiv, 112/1919 und 443/1919). Die Holztäfelung, die großen eingebauten Spiegel mit einbegriffen, bleib aber als Firmenbesitz im Sitzungssaal des Museums.

7 Cf. ausführlicher zum Thema Ottillinger 1994, pp. 73-75; Fliedl, Gottfried: Kunst und Lehre am Beginn der Moderne. Die Wiener Kunstgewerbeschule 1867-1918. Salzburg-Wien: Residenz 1986, p. 143; Rostás 2010, pp. 99-130.

${ }^{78}$ Loos, Adolf: Möbel. In: Neue Freie Presse v. 2. Oktober 1898, p. 6, auch in: ders.: Die Schriften 1897-1900. Hg. v. Adolf Opel, Wien-Klosterneuburg: Edition Va Bene 2004, pp. 184-188, hier p. 187.

${ }^{79}$ Erzherzog Rainer trat am 4. November 1898 von seiner Schirmherrschaft beleidigt zurück (MAK, Archiv 951/1898).

${ }^{80} \mathrm{Cf}$. Versammlung des Wiener Kunstgewerbevereines. In: Fremden-Blatt v. 7. Dezember 1898, p. 10.

${ }^{81}$ Cf. Fliedl 1986, pp. 147-148; Pokorny-Nagel, Kathrin: Zur Gründungsgeschichte des k. k. österreichischen Museums für Kunst und Industrie. In: Noever (Hg.) 2000, pp. 87-88. 
PÉTER ROSTÁS

Acta Hist. Art., Tom. 54, 2013 